\title{
Resilience and Vulnerability to Trauma: Early Life Interventions Modulate Aversive Memory Reconsolidation in the Dorsal Hippocampus
}

\begin{abstract}
Natividade de Sá Couto-Pereira ${ }^{1,2,3 *}$, Carine Lampert ${ }^{1}$, Aline dos Santos Vieira ${ }^{2}$, Camilla Lazzaretti ${ }^{2 \dagger}$, Grasielle Clotildes Kincheski ${ }^{3 \dagger}$, Pablo Javier Espejo ${ }^{4}$, Victor Alejandro Molina ${ }^{4}$, Jorge Alberto Quillfeldt ${ }^{2,5}$ and Carla Dalmaz ${ }^{1,2,3}$
\end{abstract}

OPEN ACCESS

Edited by:

Oliver Stork,

Medizinische Fakultät,

Universitätsklinikum Magdeburg,

Germany

Reviewed by:

Iris Müller,

Purdue University, United States

Irit Akirav,

University of Haifa, Israel

*Correspondence:

Natividade de Sá Couto-Pereira

natividade.pereira@gmail.com

tPresent address:

Camilla Lazzaretti,

Centro Universitário Cenecista de Osório-UNICNEC, Osório, Brazil,

Grasielle Clotildes Kincheski,

Instituto de Bioquímica Médica Leopoldo de Meis, Universidade Federal do Rio de Janeiro, Rio de

Janeiro, Brazil

Received: 06 November 2018 Accepted: 09 May 2019 Published: 28 May 2019

Citation:

Couto-Pereira NS, Lampert C, Vieira AS, Lazzaretti C, Kincheski GC

Espejo PJ, Molina VA, Quillfeldt JA and Dalmaz C (2019) Resilience and

Vulnerability to Trauma: Early Life Interventions Modulate Aversive Memory Reconsolidation in the Dorsal Hippocampus.

Front. Mol. Neurosci. 12:134. doi: 10.3389/fnmol.2019.00134
${ }^{1}$ Programa de Pós-graduação em Ciências Biológicas: Bioquímica, Instituto de Ciências Básicas da Saúde (ICBS), Universidade Federal do Rio Grande do Sul (UFRGS), Porto Alegre, Brazil, ${ }^{2}$ Programa de Pós-graduação em Neurociências, Instituto de Ciências Básicas da Saúde (ICBS), Universidade Federal do Rio Grande do Sul (UFRGS), Porto Alegre, Brazil, ${ }^{3}$ Departamento de Bioquímica, Instituto de Ciências Básicas da Saúde (ICBS), Universidade Federal do Rio Grande do Sul (UFRGS), Porto Alegre, Brazil, ${ }^{4}$ Instituto de Farmacología Experimental de Córdoba, Universidad Nacional de Cordoba (UNC), Cordoba, Argentina, ${ }^{5}$ Departamento de Biofísica, Instituto de Biociências, Universidade Federal do Rio Grande do Sul (UFRGS), Porto Alegre, Brazil

Early life experiences program lifelong responses to stress. In agreement, resilience and vulnerability to psychopathologies, such as posttraumatic stress disorder (PTSD), have been suggested to depend on the early background. New therapies have targeted memory reconsolidation as a strategy to modify the emotional valence of traumatic memories. Here, we used animal models to study the molecular mechanism through which early experiences may later affect aversive memory reconsolidation. Handling $(\mathrm{H})$ - separation of pups from dams for 10 min-or maternal separation (MS) - 3-h separation - were performed from PDN1-10, using non-handled $(\mathrm{NH})$ litters as controls. Adult males were trained in a contextual fear conditioning (CFC) task; $24 \mathrm{~h}$ later, a short reactivation session was conducted in the conditioned or in a novel context, followed by administration of midazolam $3 \mathrm{mg} / \mathrm{kg}$ i.p. (mdz), known to disturb reconsolidation, or vehicle; a test session was performed $24 \mathrm{~h}$ after. The immunocontent of relevant proteins was studied 15 and 60 min after memory reactivation in the dorsal hippocampus $(\mathrm{dHc})$ and basolateral amygdala complex $(\mathrm{B} L \mathrm{~A})$. Mdz-treated controls $(\mathrm{NH})$ showed decreased freezing to the conditioned context, consistent with reconsolidation impairment, but $\mathrm{H}$ and MS were resistant to labilization. Additionally, MS males showed increased freezing to the novel context, suggesting fear generalization; $\mathrm{H}$ rats showed lower freezing than the other groups, in accordance with previous suggestions of reduced emotionality facing adversities. Increased levels of Zif268, GluN2B, $\beta$-actin and polyubiquitination found in the BLA of all groups suggest that memory reconsolidation was triggered. In the $\mathrm{dHc}$, only $\mathrm{NH}$ showed increased Zif268 levels after memory retrieval; also, a delay in ERK1/2 activation was found in $\mathrm{H}$ and MS animals. We showed here that reconsolidation of a contextual fear memory is insensitive to interference by a GABAergic drug in adult male rats exposed to different neonatal experiences; surprisingly, we found 
no differences in the reconsolidation process in the BLA, but the $\mathrm{dHc}$ appears to suffer temporal desynchronization in the engagement of reconsolidation. Our results support a hippocampal-dependent mechanism for reconsolidation resistance in models of early experiences, which aligns with current hypotheses for the etiology of PTSD.

\section{Keywords: neonatal handling, maternal separation, fear memory, reconsolidation, dorsal hippocampus,} basolateral amygdala

\section{INTRODUCTION}

Early life experiences modify the development of neural circuits, impacting the individuals on cognitive and emotional levels (Bolton et al., 2017) and may program the development of vulnerability or resilience to psychopathologies later in life (Franklin et al., 2012; Singh-Taylor et al., 2015; Di Segni et al., 2018). In fact, childhood adversities appear to be at the origin of a significant portion of mental disorders (Kessler et al., 2010), with particular relevance to posttraumatic stress disorder (PTSD). Stressful early life experiences have been proposed to induce an emotional dysregulation scenario that renders individuals more susceptible to develop this disorder after exposure to a traumatic event (Lanius et al., 2010). PTSD is a complex disorder that has lately been regarded as a memory disease (Van Marle, 2015); recent therapeutical approaches to PTSD have targeted reconsolidation as a strategy to modify the emotional valence of traumatic memories (Hartley and Phelps, 2010; Schiller et al., 2010; Akirav and Maroun, 2013; Kindt and van Emmerik, 2016; Dunbar and Taylor, 2017; Elsey and Kindt, 2017), but much more research is necessary to resolve conflicting results. In light of this, resistance to reconsolidation, a phenomenon that can be observed under certain conditions (Tronson and Taylor, 2007), might present both a challenge to the reconsolidation-based therapies, as well as a hypothetical pathological mechanism contributing to PTSD, since patients constantly and involuntarily evoke the traumatic memory but for some reason are incapable of modifying its emotional valence.

While the effects of early interventions on aversive memory acquisition, recall and extinction have been well studied in rodents (Wilber et al., 2009; Kosten et al., 2012; Diehl et al., 2014), to our knowledge, only one study has evaluated the effects of early stress on aversive memory reconsolidation (Villain et al., 2018), but in that study gestational and prepubertal stress was applied. The rodent neonatal period corresponds to early childhood in humans (Eiland and Romeo, 2013), an important period of the development that has been viewed as extremely relevant for the development of vulnerability or resilience to psychopathologies (Singh-Taylor et al., 2015); external interventions in this period, such as handling $(\mathrm{H})$ or maternal separation (MS) modify the dynamics of dam-pup interaction in rats (Couto-Pereira et al., 2016), resulting in useful models to study the effects of early experiences on traumatic memories (Diehl et al., 2012, 2014).

Memory reconsolidation seems to comprise two distinct but entangled processes. First, the reactivated memory is destabilized and the trace becomes again labile; this process appears to depend on protein degradation via the ubiquitin-proteasome system-UPS, at least in the basolateral amygdala complex-BLA (Artinian et al., 2008; Lee et al., 2008; Jarome et al., 2011, 2016; Sol Fustiñana et al., 2014). NMDA receptors (NMDARs) activity is required for memory destabilization in the BLA, as shown by the administration of selective antagonists (Ben-Mamou et al., 2006; Milton et al., 2008). Further studies have shown that GluN2B-containing NMDARs are specifically involved with protein degradation via the UPS through activation of the calcium-calmodulin dependent protein kinase II (CaMKII), which in turn, activates the UPS (Mao et al., 2008; Jarome et al., 2016). The reconsolidation theory postulates that memory destabilization is followed by a restabilization phase that has been repeatedly shown to depend on protein synthesis (Nader et al., 2000; Pedreira et al., 2002; Artinian et al., 2008; Akirav and Maroun, 2013). Hence, activity-inducible transcription factors, such as Zif268, appear to be necessary for memory reconsolidation (Bozon et al., 2003; Maddox et al., 2011; Besnard et al., 2013).

Retrieval-induced labilization renders the memory susceptible to external or internal interferents, which may disrupt or update the original memory. Benzodiazepines (BZD), $\mathrm{GABA}_{\mathrm{A}}$ receptor $\left(\mathrm{GABA}_{\mathrm{A}} \mathrm{R}\right)$ positive allosteric modulators, have long been known for their amnestic properties (Malkani and Rosen, 2000), and their use as reconsolidation interferents has brought some interesting insights about the process (Makkar et al., 2010). In particular, midazolam (mdz), a rapid absorption BZD, has been applied in studies that focus on stress-modulatory effects on memory reconsolidation (Zhang and Cranney, 2008; Bustos et al., 2010; Ortiz et al., 2015; Espejo et al., 2016). These studies have shown that stress previous to training renders aversive memories resistant to reconsolidation (Bustos et al., 2010; Hoffman et al., 2015; Ortiz et al., 2015; Espejo et al., 2016), hypothetically by increasing memory strength, a feature that has been associated with decrease in NMDAR-mediated glutamatergic neurotransmission, particularly the GluN2B subunit (Wang et al., 2009), in the BLA (Ortiz et al., 2015; Espejo et al., 2016). These observations are in accordance with the essential role the amygdala plays in processing the emotional content of memories (LeDoux, 2003). In addition to the amygdala, the hippocampus, particularly its dorsal region-dorsal hippocampus ( $\mathrm{dHc})$, also has a relevant part in encoding and retrieving context-conditioned emotional memories (Phillips and LeDoux, 1992; Richter-Levin and Akirav, 2000). Both $\mathrm{H}$ and MS impact the development of the BLA and $\mathrm{dHc}$, leading to morphological and functional changes in adulthood (Andersen and Teicher, 2004; Stevenson et al., 
2009; Lajud et al., 2012; Diehl et al., 2014; Daskalakis et al., 2015; Koe et al., 2016).

Considering the long-term effects of neonatal interventions on emotionality and brain functioning, we hypothesized that $\mathrm{H}$ and MS adult rats could show changes in the reconsolidation of aversive memories, possibly resulting of alterations in signaling pathways, protein degradation and synaptic density dynamics associated with reconsolidation, in the BLA or dHc. Identifying mechanistic failures in the reconsolidation process may contribute to better understand the vulnerability to PTSD observed in individuals that suffered childhood adversities, as well as help improve reconsolidation-based therapies for the treatment of PTSD.

\section{MATERIALS AND METHODS}

\section{Subjects}

All procedures were approved by the institutional Research Ethics Committee (CEUA-UFRGS \#23844) and followed the Brazilian Law regarding the use of animals (Federal Law 11.794/2008) and the Guidelines for the Care and Use of Mammals in Neuroscience and Behavioral Research (National Research Council 2003). Care was taken to minimize animal suffering during the experiments.

Primiparous pregnant Wistar rats bred at our animal facility were used. At gestational day 17-18, they were single-housed in home cages made of Plexiglas $(38 \times 32 \times 17 \mathrm{~cm})$ with sawdustcovered floors and kept in a controlled environment (lights on from 7:00 to 19:00, temperature at $22 \pm 2^{\circ} \mathrm{C}$, standard rat chow and water provided ad libitum). The day of birth was considered postnatal day 0 (PND 0). All litters were randomly culled to 6-8 pups within $24 \mathrm{~h}$ after birth and were randomly assigned to one of the neonatal interventions described below. Weaning was performed on PND 21: males were randomly housed 3-4 per cage and remained under standard animal facility conditions until the beginning of the experiments.

To minimize the influence of each litter genetic load on our results, as adults, siblings were distributed among the various treatments: a maximum of two males from the same litter were assigned to the same drug or reactivation protocol for behavioral experiments and for biochemical experiments, only one male/litter was used in the same reactivation protocol. Females were assigned to other projects.

\section{Neonatal Intervention Models}

Non-handled group (NH): pups and dams were left undisturbed until weaning, except for cage cleaning.

Neonatal Handling group (H): from PND 1-10, once a day, pups were gently placed together in a clean box lined with a paper towel, in a warm bath set to $32^{\circ} \mathrm{C}$, where they remained for $10 \mathrm{~min}$. After this period, pups were returned to their respective cages. This procedure was performed during the lights-on cycle, between 12:00 and 13:00.

Maternal separation group (MS): same protocol as the $\mathrm{H}$ group, except pups remained in the warm bath for $3 \mathrm{~h}$ and this intervention was conducted between 14:15 and 17:30.
Each litter had its own glove to be manipulated with, to avoid the spread of odors between nests. During the interventions, dams remained in the homecage, inside the room, so they could hear the pups' vocalizations. From birth to weaning, cage cleaning was performed only when necessary, similarly for all groups: dirty sawdust was carefully removed from the cage, avoiding the nest area, and replaced with clean sawdust. Neither the dam nor the pups were disturbed during this process.

\section{Contextual Fear Conditioning}

The contextual fear conditioning (CFC) task was performed on male rats, aged PND 90-100, that were subjected to the neonatal interventions described above. Experiments took place from 9:00 to 13:00. Two days before the beginning of the task, animals were taken to the room where they remained for $2 \mathrm{~h}$, for acclimation; at the end of this period, they were gently handled and weighted: $\mathrm{NH}-397.3 \pm 30.9 ; \mathrm{H}-401.0 \pm 36.7$; MS-412.2 \pm 38.2 [mean \pm standard deviation; $F_{(2,99)}=1.302$, $p=0.277,1 \mathrm{w}$-analysis of variance (ANOVA) .

CFC was performed in a wooden lidded apparatus $(220 \times 280 \times 260 \mathrm{~mm})$, with a transparent plastic wall, and a grid floor of parallel stainless steel bars $1.0 \mathrm{~cm}$ spaced (context A). In the training session, rats were allowed $3 \mathrm{~min}$ free exploration, to ensure they would form and consolidate a coherent representation of the context (Fanselow and Dong, 2010); animals then received three $1 \mathrm{~s}$-duration footshocks of $0.8 \mathrm{~mA}, 30 \mathrm{~s}$-interval, and $1 \mathrm{~min}$ later they were placed in clean homecages, to avoid contact with animals waiting to be trained. The electric current intensity was chosen based on a previous flinch-jump test (Couto-Pereira et al., 2016) and corresponds to an intensity to which $\mathrm{NH}, \mathrm{H}$ and MS males all exhibited a jump response.

Two different Reactivation (React) sessions were conducted, $24 \mathrm{~h}$ after training. In the React A session, 55 animals $(\mathrm{NH}-20$; $\mathrm{H}-17$; MS - 18) were re-exposed to context A, for $5 \mathrm{~min}$. In the pseudo React B, 47 animals (NH-15; H-16; MS - 16) were exposed to an unfamiliar context (B) for $5 \mathrm{~min}$, which consisted of a plastic transparent box $(400 \times 220 \times 260 \mathrm{~mm})$ with smooth floor and walls, placed in a different room. Immediately after the end of both React sessions, animals received an intraperitoneal injection (i.p.) of either sterile saline solution-sal $1 \mathrm{~mL} / \mathrm{kg}$ or mdz ("Dormonid," Produtos Roche Químicos e Farmacêuticos, Brazil) diluted in sterile saline solution to a concentration of $3 \mathrm{mg} / \mathrm{mL}$ and administered at a dosage of $3 \mathrm{mg} / \mathrm{kg}$. Twenty-four hours later, a Test session was conducted with all animals, in context A, for $5 \mathrm{~min}$. All React and Test sessions were recorded; the training sessions of 39 animals $(\mathrm{NH}-13$; $\mathrm{H}-13$; MS-13) from the 15 min cyt experiment (described below) were recorded for baseline freezing assessment. Freezing duration, defined as the total absence of body and head movement except for that associated with breathing (Blanchard and Blanchard, 1969), was later scored by a single experimenter, whose analysis was compared with another experimenter for inter-reliability (Intraclass correlation coefficient $=0.988$ ). Freezing is expressed in percentage of total session time. 


\section{Biochemical Analyses}

To evaluate the reconsolidation process at a molecular level, animals were euthanized at two different time points: 15 and $60 \mathrm{~min}$ after the end of a 5-min Reactivation session in the context A (React), with non re-exposed animals as controls (No React). No drugs were administered in this experiment. The 60 min post React experiment was divided into two experiments to obtain the cytosolic fraction (cyt) and, in a different subset of animals, a synaptosomal membrane-enriched fraction (synapt). A different subset of animals was euthanized at PND 90, without undergoing any experimental procedure except for the neonatal interventions (naïve). Adult male animals, weighing $381 \pm 35 \mathrm{~g}$ (mean \pm standard deviation), which were subjected to the neonatal interventions described above, were divided as follows: 15 min cyt-NH: 13 (React-6; No React-7), H: 13 (React-8; No React-5), MS: 14 (React-7; No React-7); 60 min cyt-NH: 16 (React-8; No React-8), H: 12 (React-6; No React-6), MS: 14 (React-6; No React-6); 60 min synapt-NH: 13 (React-6; No React-7), H: 12 (React-6; No React-6), MS: 11 (React-6; No React-5); naïve cyt-NH: 7; H: 8; MS: 6. Experiments were performed from 9:00 to 13:00.

\section{Brain Dissection}

Fresh brain tissue was dissected on ice. To dissect the $\mathrm{dHc}$ and BLA, coronal brain slices of $2 \mathrm{~mm}$ were cut using an acrylic brain matrix (\#AL-1160, Alto). Structure boundaries were identified using a rat brain atlas (Paxinos and Watson, 1998): the dorsal portion of the hippocampus $(\mathrm{dHc})$ was dissected from slices from bregma $-2 \mathrm{~mm}$ to approximately bregma $-5.52 \mathrm{~mm}$ and slices between approximately bregma $-2 \mathrm{~mm}$ and $-4 \mathrm{~mm}$ were used for the BLA, which was dissected using a $2 \mathrm{~mm}$-diameter punch. Once dissected, samples were immediately frozen in liquid nitrogen and later stored at $-80^{\circ} \mathrm{C}$ until further analysis.

\section{Tissue Fractionation and Protein Extraction Cyt Fraction}

Samples were homogenized in 1:10 (w:v) hypotonic $10 \mathrm{mM}$ Hepes buffer, containing $1.5 \mathrm{mM} \mathrm{MgCl}_{2}, 10 \mathrm{mM} \mathrm{KCl}$, 1 mM EDTA, 1 mM DTT, protease inhibitor (\#11697498001, Roche, Germany) and phosphatase inhibitor (\#88667, Pierce, ThermoFisher Scientific, Waltham, MA, USA) cocktails, $\mathrm{pH}=7.9,4^{\circ} \mathrm{C}$. Samples were incubated on ice for $15 \mathrm{~min}$ to allow cell swelling; Nonidet P-40 0.6\% (\#E109, Amresco, Cleveland, $\mathrm{OH}$, USA) was added and samples were placed on ice for $5 \mathrm{~min}$ more, with agitation every $15 \mathrm{~s}$. Homogenates were centrifuged at $10,000 \mathrm{~g}$, for $10 \mathrm{~min}$, at $4^{\circ} \mathrm{C}$, and the supernatant containing the cytosolic proteins was collected. Total protein content was determined using the PierceTM BCA Protein Assay kit (\#23227, ThermoFisher Scientific, Waltham, MA, USA).

\section{Synapt Fraction}

Crude synaptosomal fractions (Synapt) of BLA and dHc were obtained based on previous studies (Dunah and Standaert, 2001; Jarome et al., 2011). This extraction method yields a fraction that is rich in synaptic membrane and synapse-associated proteins (Dunah and Standaert, 2001). Briefly, samples were thawed on ice and then homogeneized in 1:10 (m/v) TEVP+sucrose buffer
[10 mM Tris-HCl, 5 mM NaF, 1 mM EDTA, 1 mM EGTA, phosphatase inhibitor cocktail (\#88667, Pierce, ThermoFisher Scientific, Waltham, MA, USA), 320 mM sucrose, $\mathrm{pH}$ 7.4], using a pestle and a glass tissue grinder. Homogenates were centrifuged at $1,000 \mathrm{~g}$ for $10 \mathrm{~min}$, at $4^{\circ} \mathrm{C}$. The supernatant was collected and centrifuged at $10,000 \mathrm{~g}$ for $10 \mathrm{~min}$, at $4^{\circ} \mathrm{C}$. The resulting pellet was ressuspended in $1 / 5$ detergent containing Lysis buffer [in $10 \mathrm{ml}$ ultra-pure $\mathrm{H}_{2} \mathrm{O}: 0.0605 \mathrm{~g}$ Tris- $\mathrm{HCl}, 0.025 \mathrm{~g}$ sodium deoxycholate, $0.0876 \mathrm{~g} \mathrm{NaCl}, 1 \mathrm{ml} 10 \%$ SDS solution, protease inhibitor (\#11697498001, Roche, Germany) and phosphatase inhibitor (\#88667, Pierce, ThermoFisher Scientific, Waltham, MA, USA) cocktails] and then centrifuged at $15,000 \mathrm{~g}$ for $5 \mathrm{~min}$, $4^{\circ} \mathrm{C}$. The supernatant containing synaptosomal membrane proteins was collected and total protein content was determined as above.

\section{Western Blot}

Denatured, reduced samples were loaded (40 $\mu \mathrm{g}$ protein/lane) on $\mathrm{NuPAGE}^{\circledR}$ precast $4-12 \%$ gradient polyacrylamide gels (\#NP0323BOX, ThermoFisher Scientific, Waltham, MA, USA), together with a $12-225 \mathrm{kDa}$ molecular weight marker (\#RPN800E, Amersham, GE Healthcare, UK). Electrophoresis and electrotransfer were performed on a XCell SureLock ${ }^{\circledR}$ Mini-Cell and XCell II ${ }^{\mathrm{TM}}$ Blot Module, respectively (\#EI0002, Invitrogen, ThermoFisher Scientific, Waltham, MA, USA). Proteins were transferred to nitrocellulose membranes [ $1 \mathrm{~h} 50$ at $50 \mathrm{~V}$ in transfer buffer (48 mM Trizma, $39 \mathrm{mM}$ glycine, $20 \%$ methanol, $0.25 \%$ SDS)] and blots were then blocked for $2 \mathrm{~h}$ in Tris-buffered saline containing tween and 5\% (m/v) non-fat dry milk or $5 \%(\mathrm{~m} / \mathrm{v})$ bovine serum albumin for phosphorylated proteins detection. Blots were incubated overnight, at $4^{\circ} \mathrm{C}$, with one of the following primary antibodies: anti-Zif268 (1:1,000, \#4154, Cell Signaling Technology, Danvers, MA, USA), anti-ERK 1/2 (1:4,000, \#ABS44, Millipore, Germany), anti-pERK 1/2 (1:2,000, \#9101, Cell Signaling Technology, Danvers, MA, USA), anti-GluN2A (1:1,000, \#M264, Sigma-Aldrich, St. Louis, MO, USA), anti-GluN2B (1:2,000, \#06600, Millipore, Germany), anti-pGluN2B (1:1,000, \#M2442, Sigma-Aldrich, USA), anti-GABA $\mathrm{A}$ Q1-6 (1:500, \#sc-376282, Santa Cruz Biotechnology, Santa Cruz, CA, USA), anti-synaptophysin (1:2,000, \#AB9272, Millipore, Germany), anti-ubiquitin k48-specific (1:500, \#05-1307, Merck-Millipore, Germany), anti- $\alpha$-tubulin (1:4,000, \#T6074, Sigma-Aldrich, St. Louis, MO, USA) or anti- $\beta$-actin (1:3,500, \#8457, Cell Signaling Technology, Danvers, MA, USA). Secondary peroxidaseconjugated anti-rabbit antibody (1:1,000, \#AP132P, MerckMillipore, Germany, or 1:2,500, Jackson ImmunoResearch, West Grove, PA, USA) or anti-mouse antibody (1:1,000, \#402335, Calbiochem, Merck-Millipore, Germany) was incubated for $2 \mathrm{~h}$ at room temperature. Blots were developed using a chemiluminescence ECL kit (\#RPN2209, Amersham, GE Healthcare, UK) and images were digitally acquired using ImageQuant LAS 4,000 (GE Healthcare Bio-Sciences $\mathrm{AB}$, Umeå, Sweden); in the $\mathrm{k} 48$-linked polyubiquitination experiment, chemiluminescence was acquired on $\mathrm{x}$-ray films. Antibody stripping was performed using $1 \mathrm{M}$ sodium hydroxide and stripping efficiency was confirmed by incubating 
blots with the respective secondary antibody, followed by chemiluminescence detection.

Optical density (OD) was determined using the software ImageJ (National Institutes of Health, Bethesda, MD, USA). Results were quantified as the ratio of the protein of interest $\mathrm{OD}$ to that of the loading control. $\beta$-actin was used as loading control for all western blot experiments except in BLA synaptosomes blots, in which $\alpha$-tubulin was used, as explained in the Results section. Loading control absolute OD was tested in all experiments for differences between groups and was only accepted if no significant interaction or main effects were found ( $p>0.05,2 \mathrm{w}$-ANOVA, data not shown). All results are expressed in percentage of control ( $\mathrm{NH}$ No Reactivation group).

\section{Statistical Analysis}

Data were analyzed using the software SPSS version 16.0. Levene's test of equality of error variances was used to test the homogeneity of group variances. Two-way analysis of variance (2w-ANOVA), with neonatal intervention and drug as factors, or one-way ANOVA (1w-ANOVA), with neonatal intervention as factors were performed for behavioral results. $2 \mathrm{w}$-ANOVA with neonatal intervention and reactivation as factors was used for all biochemical results, except for the analysis of naïve animals, in which a 1w-ANOVA was used. Tukey post hoc test was performed to compare groups, when appropriate. Data are expressed as mean \pm standard error of the mean (SEM). Statistical significance was set at $p<0.05$. Data was excluded from behavioral experiments only if freezing was more than 2 standard deviations from the group mean. A total of four animals was excluded using this criteria: $2 \mathrm{NH}$, $1 \mathrm{H}$ and $1 \mathrm{MS}$.

\section{RESULTS}

\section{Mdz Disrupts Memory Reconsolidation in NH but Not in $\mathrm{H}$ and MS Adult Male Rats}

To study the effects of different neonatal interventions on aversive memory reconsolidation, we first established a protocol that triggered contextual fear memory reconsolidation in male adult rats. We used $\mathrm{mdz}$, a GABAergic drug known to interfere with memory reconsolidation (Bustos et al., 2006), to provide behavioral evidence that the protocol used was inducing reconsolidation, by testing animals $24 \mathrm{~h}$ later in context A, for $5 \mathrm{~min}$ (Figure 1A). A significant interaction between neonatal intervention and drug was found for freezing, in the Test session $\left(F_{(2,48)}=4.108, p=0.023,2 \mathrm{w}\right.$-ANOVA); no significant main effects were found (neonatal intervention: $F_{(2,48)}=2.012, p=0.145$; drug: $F_{(2,48)}=1.143, p=0.290$; $2 \mathrm{w}$-ANOVA). Post hoc analysis revealed that $\mathrm{NH}$ animals that were administered mdz $3 \mathrm{mg} / \mathrm{kg}$ after React had freezing levels significantly lower than $\mathrm{NH}$ rats that received sal $(p=0.040$, Tukey post hoc test), showing that $\mathrm{mdz}$ administered during the reconsolidation window successfully disrupted memory in $\mathrm{NH}$ rats and providing evidence that the experimental conditions employed here successfully induced memory reconsolidation in control animals (Figure 1C).

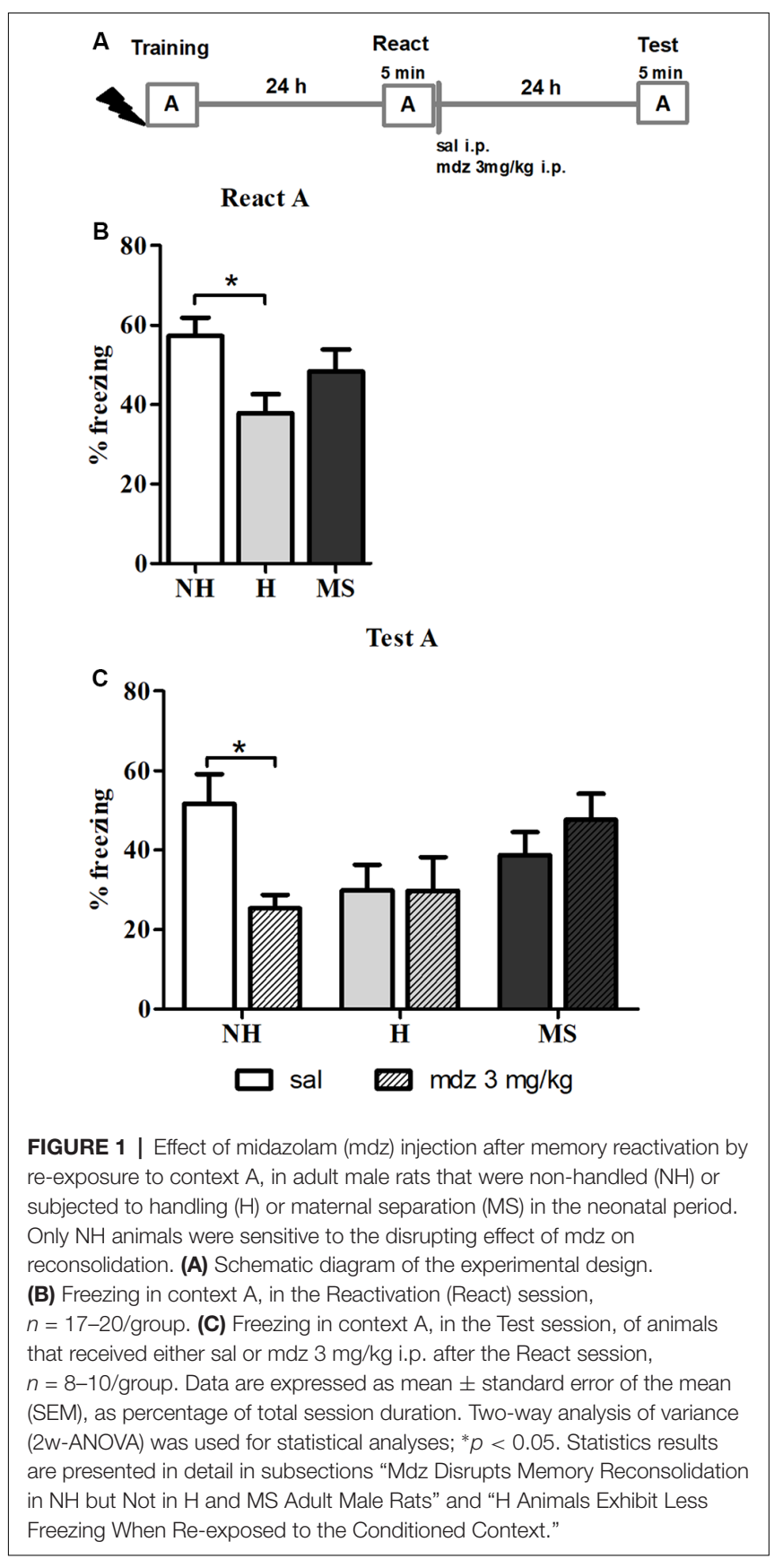

Furthermore, neonatal interventions appeared to affect this process; there were no differences in freezing between sal or mdz-treated $\mathrm{H}$ and MS rats $(p=1.000$ and $p=0.937$, respectively; Tukey post hoc test), suggesting that fear memory in these animals was resistant to interference by a $G_{A B A} R$ positive allosteric modulator.

\section{H Animals Exhibit Less Freezing When Re-exposed to the Conditioned Context}

In the React A session (Figure 1B), a significant effect of neonatal intervention was found $\left(F_{(2,52)}=3.448, p=0.039,1 \mathrm{w}\right.$-ANOVA); Tukey post hoc revealed that $\mathrm{H}$ animals exhibited significantly 
less freezing than $\mathrm{NH}(p=0.030)$, but no differences were detected between MS and NH rats $(p=0.516)$ or MS and $\mathrm{H}$ rats $(p=0.325)$, which is in accordance with previous studies on aversive memory consolidation in $\mathrm{H}$ and MS rats (Meerlo et al., 1999; Ladd et al., 2004; Kosten et al., 2006; Diehl et al., 2007; Arnett et al., 2015).

Context-induced freezing may be influenced by the emotional valence of the aversive experience or by pain sensitivity. Regarding training strength, we have previously reported that $0.8 \mathrm{~mA}$ is an electric current intensity that generates similar behavioral responses and corticosterone secretion levels after conditioned context exposure in $\mathrm{NH}, \mathrm{H}$ and MS male rats; also, no differences on footshock sensitivity were observed in these groups in the flinch-jump test (Couto-Pereira et al., 2016).

\section{MS Rats Generalize the Fear Response to Novel Environments}

Memory precision was tested by exposing the animals to an unfamiliar context $24 \mathrm{~h}$ after training -pseudo React in context $B$ (Figure 2B). A significant effect of neonatal intervention was detected $\left(F_{(2,42)}=4.102, p=0.027,1 \mathrm{w}\right.$-ANOVA); Tukey post hoc analysis showed that MS rats freezing was significantly increased in the new context compared to $\mathrm{H}$ animals $(p=0.020)$, suggesting that MS induces generalization of fear memory, at least in comparison to $\mathrm{H}$; no differences were found between $\mathrm{H}$ and MS rats compared to controls ( $p=0.339$ and $p=0.448$, respectively).

Regarding this result, anxiety could be a confounding factor, since several studies reported that MS animals show increased anxiety-like behaviors in unfamiliar environments (Romeo et al., 2003; de Kloet et al., 2005; Makena et al., 2012); hence, freezing in context B could result of novelty-induced anxiety. To test this hypothesis, we examined freezing in the training session, during the 3 min pre-shock, when animals were exploring a context that was new to them at that moment. Consistent with our previous report (Diehl et al., 2014), before conditioning, neonatal interventions did not change freezing in response to a new environment: $\mathrm{NH}-1.3 \% \pm 0.5, \mathrm{H}-0.9 \% \pm 0.5$, MS $-1.0 \% \pm 0.5$ ( $n=13$ /group). Since no differences were found at this point $\left(F_{(2,36)}=0.224, p=0.801,1 \mathrm{w}\right.$-ANOVA $)$, it is valid to assume that the aversive experience was necessary to induce the generalization of fear to unconditioned environments observed in MS rats.

\section{Mdz Disrupting Effect on Reconsolidation Requires Properly Reactivated Memories}

The pseudo React B session was also performed to evaluate the specificity of the effect of $\mathrm{mdz}$ on memory reconsolidation. After exposure to context $\mathrm{B}$, sal or $\mathrm{mdz} 3 \mathrm{mg} / \mathrm{kg}$ i.p. was injected and $24 \mathrm{~h}$ later, animals were re-exposed to the conditioned context (A) for 5 min (Figures 2A,C). No significant interaction or main effects were detected (interaction: $F_{(2,39)}=0.143$, $p=0.867$; neonatal intervention: $F_{(2,39)}=1.155, p=0.326$; drug: $F_{(1,39)}=1.474, p=0.232 ; 2 \mathrm{w}$-ANOVA). Consistently with previous reports (Bustos et al., 2006, 2009), mdz only impaired memory when it was properly reactivated in the conditioned

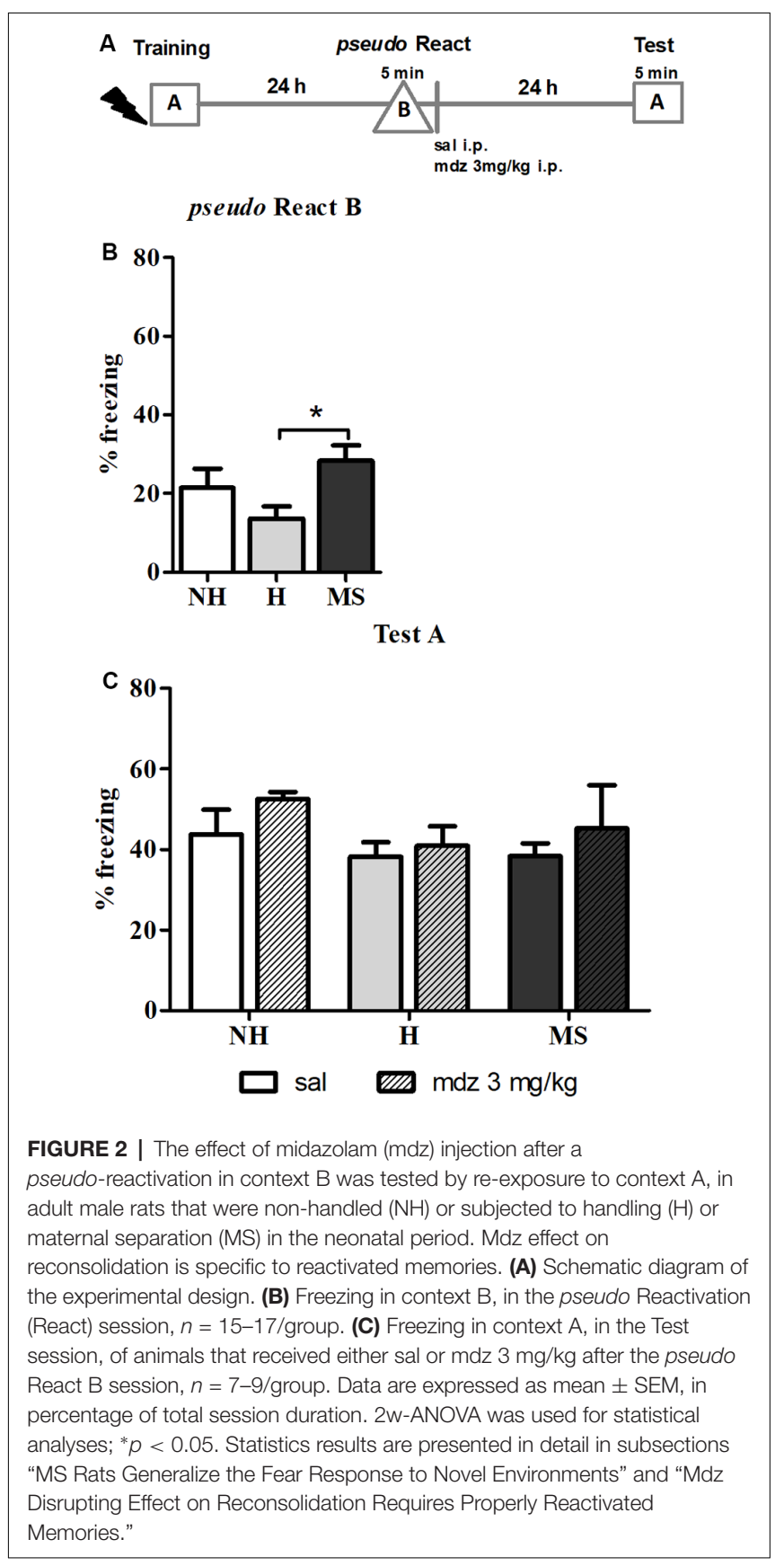

context (A), providing further evidence of the specific effect of the drug in disrupting memory reconsolidation after retrieval.

\section{ERK 1/2 Activity and Zif268 Levels Were Not Changed in the BLA 15 min After Aversive Memory Reactivation}

To better understand the resistance to reconsolidation interference in $\mathrm{H}$ and MS rats, a different subset of animals was trained and re-exposed to the conditioned apparatus $\mathrm{A}$ (React) and $24 \mathrm{~h}$ later $\mathrm{dHc}$ and BLA were collected 15 or $60 \mathrm{~min}$ after the end of the session; since the goal of this set of experiments was to evaluate biochemical changes during 
reconsolidation induced by reactivation, animals that were trained but not re-exposed to the context (No React) were used as controls (Figure 3A).

ERK $1 / 2$ levels, as well as its active form phosphorylated at residues T202/Y204, were evaluated by Western blot, $15 \mathrm{~min}$ after the end of the Reactivation session, in the BLA of $\mathrm{NH}, \mathrm{H}$ and MS adult males (Figures 3B-D,F). No significant interaction or main effects were found for ERK $1 / 2$ or its phosphorylated form $\left(\right.$ ERK $1 / 2$ : interaction $-F_{(2,33)}=0.929$, $p=0.405$; neonatal intervention $-F_{(2,33)}=0.946, p=0.399$; reactivation $-F_{(1,33)}<0.001, p=0.991$; pERK $1 / 2$ : interaction: $F_{(2,33)}=0.074, p=0.929$; neonatal intervention $-F_{(2,33)}=0.576$, $p=0.568$; reactivation $-F_{(1,33)}=2.465, p=0.127 ; 2 \mathrm{w}$-ANOVA). BLA ERK $1 / 2$ activation happens later than in the $\mathrm{dHc}$, reaching a peak at 30 min post-reactivation (Besnard et al., 2014). Similarly, we did not find any significant differences in Zif268 levels at this time point (Figures 3E,F; interaction: $F_{(2,30)}=0.107, p=0.899$; neonatal intervention: $F_{(2,30)}=0.516, p=0.602$; reactivation: $F_{(1,30)}=2.516, p=0.123 ; 2 \mathrm{w}$-ANOVA).

\section{Zif268 Levels Increase in the BLA, 60 min After Aversive Memory Reactivation}

The immunocontent of Zif268 was also analyzed $60 \mathrm{~min}$ post-reactivation (Figures 4A,B,D), a time point at which higher increases in the BLA have been reported (Besnard et al., 2014). In fact, we found significantly increased levels of Zif268 in $\mathrm{NH}, \mathrm{H}$ and MS rats that were exposed to context A, compared to No React controls $\left(F_{(1,35)}=19.965, p<0.01,2 \mathrm{w}\right.$-ANOVA, main effect of Reactivation). Zif268 induction has been implicated in the memory reconsolidation process in several studies (Hall et al., 2001; Bozon et al., 2003; Lee et al., 2004; Maddox et al., 2011; Besnard et al., 2013; Espejo et al., 2016). No interaction or main effect of neonatal intervention were found (interaction: $F_{(2,35)}=1.995, p=0.151$; neonatal intervention: $F_{(2,35)}=0.761$, $p=0.475 ; 2 \mathrm{w}-\mathrm{ANOVA})$.

\section{Memory Reactivation Induces Changes in Receptor Composition at the BLA Synapses}

NMDAR subunits GluN2A and GluN2B (total and phosphorylated form), $\mathrm{GABA}_{\mathrm{A}} \mathrm{R}$ subunits $\alpha 1-6$ and $\beta$-actin were analyzed in the BLA synapt fraction, $60 \mathrm{~min}$ post-reactivation (Figure 5A).

The immunocontent of GluN2B, pGluN2B, GluN2A and $\mathrm{GABA}_{\mathrm{A}} \mathrm{R} \quad \alpha 1-6$ subunits was significantly increased in the synapt fraction by memory reactivation (GluN2B: $F_{(1,25)}=12.861, p=0.001$; pGluN2B: $F_{(1,25)}=8.311$, $p=0.009$; GluN2A: $F_{(1,25)}=4.225, p=0.050 ; 2 \mathrm{w}$-ANOVA, main effect of reactivation). For GluN2A, a trend towards an interaction was also found $\left(F_{(2,25)}=2.575, p=0.098\right.$, $2 \mathrm{w}$-ANOVA). No significant interactions or main effects of neonatal intervention were found for the other receptor subunits analyzed here (GluN2B: interaction $-F_{(2,25)}=1.909$, $p=0.169$; neonatal intervention $-F_{(2,25)}=0.764 ; p=0.476$; pGluN2B: interaction $-F_{(2,25)}=0.095, p=0.910$; neonatal intervention $-F_{(2,25)}=0.287 ; p=0.753$; GluN2A: neonatal intervention $-F_{(2,25)}=0.505 ; p=0.610 ; 2 \mathrm{w}$-ANOVA).
Phosphorylation of GluN2B subunit was assessed at its major phosphorylation site, Y1472 (Chen and Roche, 2007). While both total and phosphorylated forms of GluN2B were significantly increased by reactivation, as described above, no interaction or main effects were found for the ratio pGluN2B/GluN2B (interaction: $F_{(2,25)}=0.978, p=0.392$; neonatal intervention: $F_{(2,25)}=0.643, p=0.536$; reactivation: $F_{(1,25)}=0.146, p=0.706 ; 2 \mathrm{w}$-ANOVA), which means that the increase in GluN2B at synapses was accompanied by its phosphorylation (Figures 5B-E,H).

A ratio of the synapt immunocontent of GluN2A/GluN2B was also calculated since it has been shown that increased GluN2A/GluN2B synaptic ratio in the BLA inhibits retrievaldependent memory destabilization (Holehonnur et al., 2016). No significant interaction or main effects were found for this ratio (interaction: $F_{(2,25)}=0.965, p=0.395$; neonatal intervention: $F_{(2,25)}=1.978, p=0.159$; reactivation: $F_{(1,25)}=0.447, p=0.510$; 2w-ANOVA, data not shown).

Since a $\mathrm{GABA}_{\mathrm{A}} \mathrm{R}$ positive allosteric modulator was used as a memory interferent in this work, it was important to assess this receptor concentration at synapses. To do so, we used an antibody that recognizes all 1-6 $\alpha$-type subunits of the $G_{A B A} R$. Since all $\mathrm{GABA}_{\mathrm{A}} \mathrm{R}$ possess two $\alpha$ subunits in their composition (Olsen and Sieghart, 2009), measurement of total levels of this subunit should provide an approximate determination of total receptor content. While a reactivation effect was observed $\left(F_{(1,30)}=5.815, p=0.022 ; 2 \mathrm{w}\right.$-ANOVA $)$, similarly to NMDAR subunits, no interaction or neonatal intervention effect was observed for this measure (interaction: $F_{(2,30)}=0.818, p=0.451$; neonatal intervention: $F_{(2,30)}=0.382, p=0.686 ; 2 \mathrm{w}$-ANOVA), suggesting that $\mathrm{GABA}_{\mathrm{A}} \mathrm{R}$ levels were not altered in the BLA synapses of $\mathrm{H}, \mathrm{NH}$ and $\mathrm{MS}$ rats before exposure to context (Figures 5F,H). This does not necessarily represent basal levels since No Reactivation rats had been trained in an aversive task 24 h earlier.

A significant reactivation-induced increase in $\beta$-actin was also found for all neonatal treatments $\left(F_{(1,30)}=8.354, p=0.007\right.$, $2 \mathrm{w}$-ANOVA, main effect of Reactivation; Figures $\mathbf{5 G - H}$ ); this effect is in accordance with previous reports that show that actin filaments proliferation is necessary for reconsolidation (Rehberg et al., 2010; Lamprecht, 2016; Lunardi et al., 2018; Popik et al., 2018). No significant interaction $\left(F_{(2,30)}=1.178\right.$, $p=0.322,2 \mathrm{w}$-ANOVA) or main effect of neonatal intervention $\left(F_{(2,30)}=0.274, p=0.762,2 \mathrm{w}\right.$-ANOVA $)$ were found. To detect a possible confounding effect on our BLA synapt results that could arise from a variation in the number or activity of synapses in our neonatal intervention groups, we measured synaptophysin levels in the BLA cyt fraction, a protein that is commonly used as pre-synaptic terminal marker (Andersen and Teicher, 2004). No significant interaction or main effects were found concerning synaptophysin levels in the BLA of $\mathrm{NH}, \mathrm{H}$ and MS adult rats (Figures 4C,D; interaction: $F_{(2,35)}=1.861, p=0.171$; neonatal intervention: $F_{(2,35)}=0.281, p=0.757$; reactivation: $F_{(1,35)}=1.047, p=0.313 ; 2 \mathrm{w}$-ANOVA).

Also as a control experiment, we analyzed the immunocontent of GluN2A, GluN2B and GABA $_{\mathrm{A}} \mathrm{R}$ subunits $\alpha 1-6$ in the BLA cyt fraction of naive $\mathrm{NH}, \mathrm{H}$ and $\mathrm{MS}$ rats, 


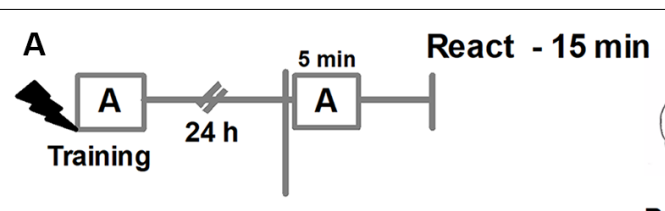

No React

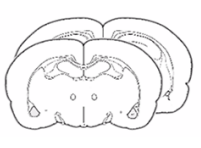

BLA15 min cyt
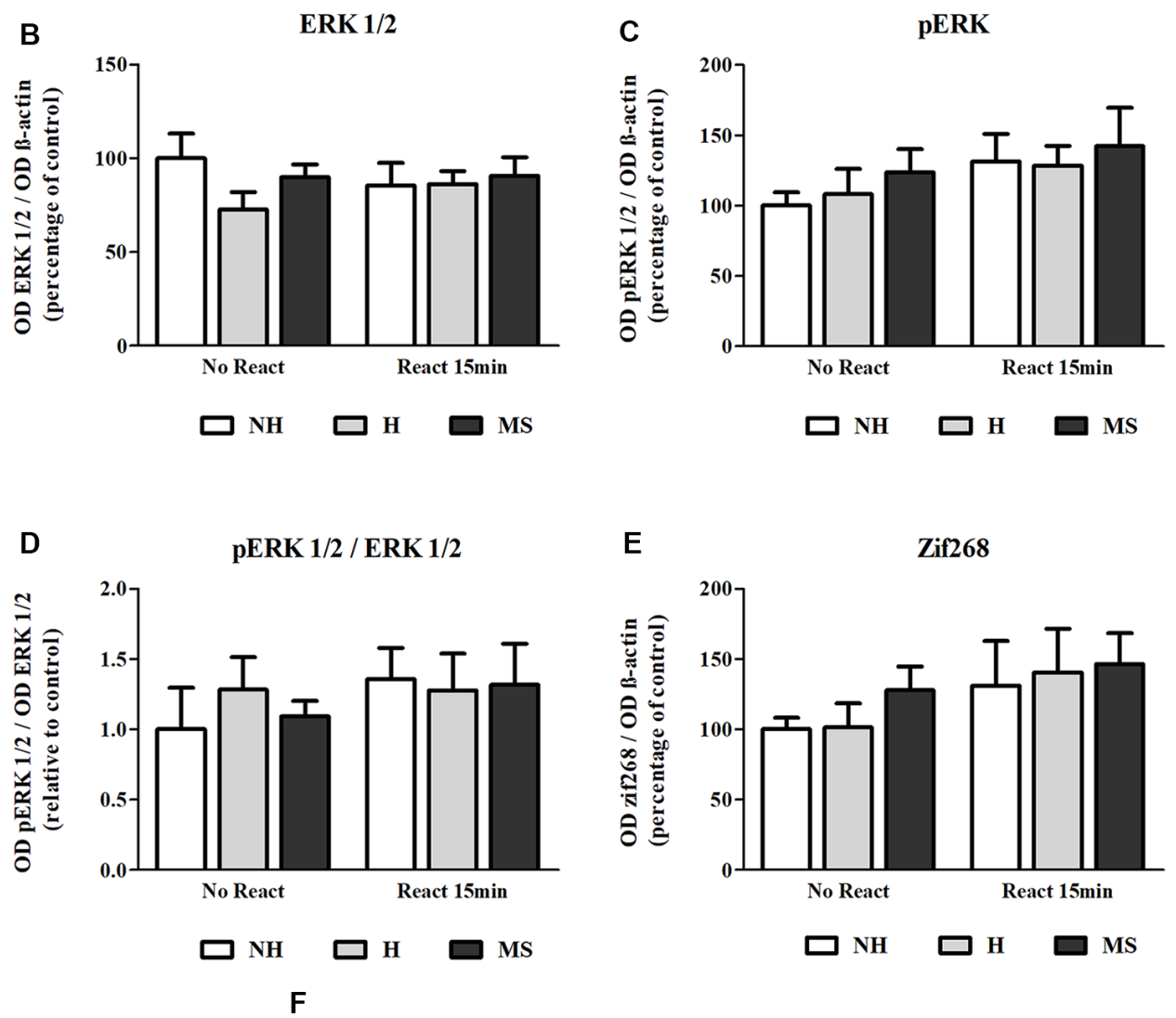

E $\quad$ Zin268
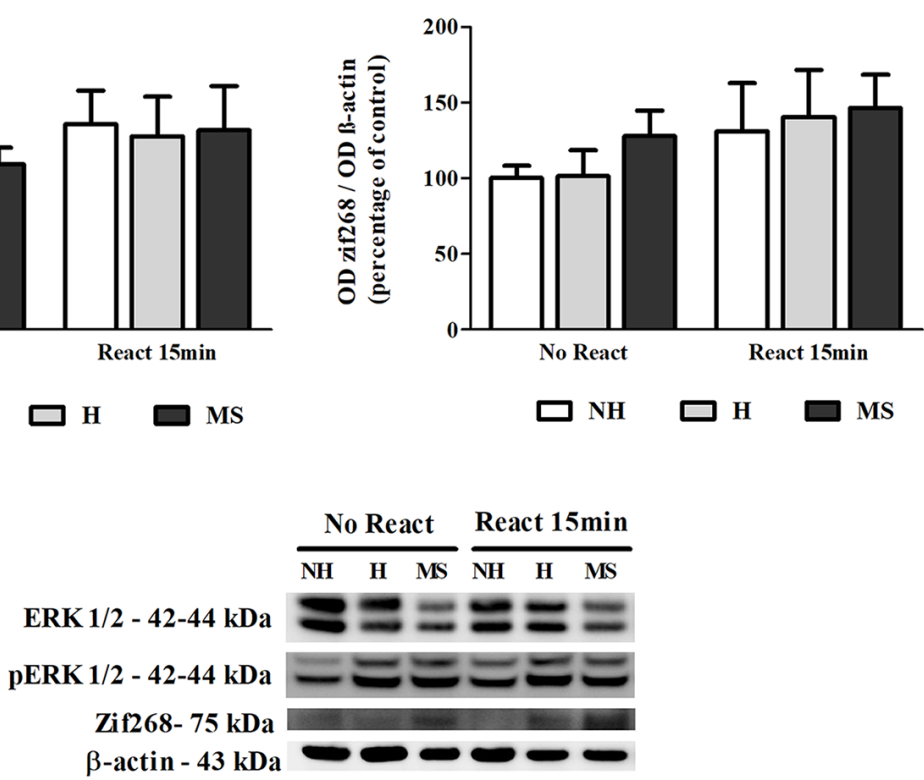

FIGURE 3 | ERK 1/2, pERK 1/2 and Zif268 immunocontent in the basolateral amygdala complex (BLA) cytosolic fraction (cyt) of adult male rats that were non-handled $(\mathrm{NH})$ or subjected to handling $(\mathrm{H})$ or maternal separation $(\mathrm{MS})$ in the neonatal period, 15 min after Reactivation (React) compared to trained animals that were not re-exposed to the training context (No React). No significant differences in ERK 1/2 activation or Zif268 expression were found in the BLA at this time point. (A) Schematic diagram of the experimental design; (B) ERK 1/2; (C) pERK 1/2; (D) calculated ratio of pERK 1/2 per ERK 1/2 immunocontent; (E) Zif268; (F) representative Western blot bands. Data are expressed as mean \pm SEM. $n=5-7 /$ group. 2W-ANOVA was used for statistical analyses. Statistics results are presented in detail in subsection "ERK 1/2 Activity and Zif268 Levels Were not Changed in the BLA 15 min After Aversive Memory Reactivation."

to check for differences which could influence our results (Figure 6A). NH animals showed a higher basal level of GluN2A compared to $\mathrm{NH}\left(F_{(2,17)}=4.045, p=0.037 ; 1 \mathrm{w}\right.$-ANOVA; Tukey post hoc: $\mathrm{NH}$ vs. $\mathrm{H}: p=0.044, \mathrm{NH}$ vs. MS: $p=0.08$; Figures 6B,E). This difference disappeared after training in the CFC paradigm, as can be seen by the H No React result (Figure 5B), although no direct comparison was made between these data. No significant differences were detected for GluN2B $\left(F_{(2,17)}=0.084\right.$, $p=0.919 ; 1 \mathrm{w}$-ANOVA; Figures 6C,E), GABA $\mathrm{A}_{\mathrm{R}}$ subunits $\alpha 1-6$ $\left(F_{(2,18)}=0.093, p=0.912 ; 1 \mathrm{w}\right.$-ANOVA; Figures 6D,E) or the ratio GluN2A/GluN2B $\left(F_{(2,16)}=1.724, p=0.210 ; 1 \mathrm{w}\right.$-ANOVA; data not shown). 

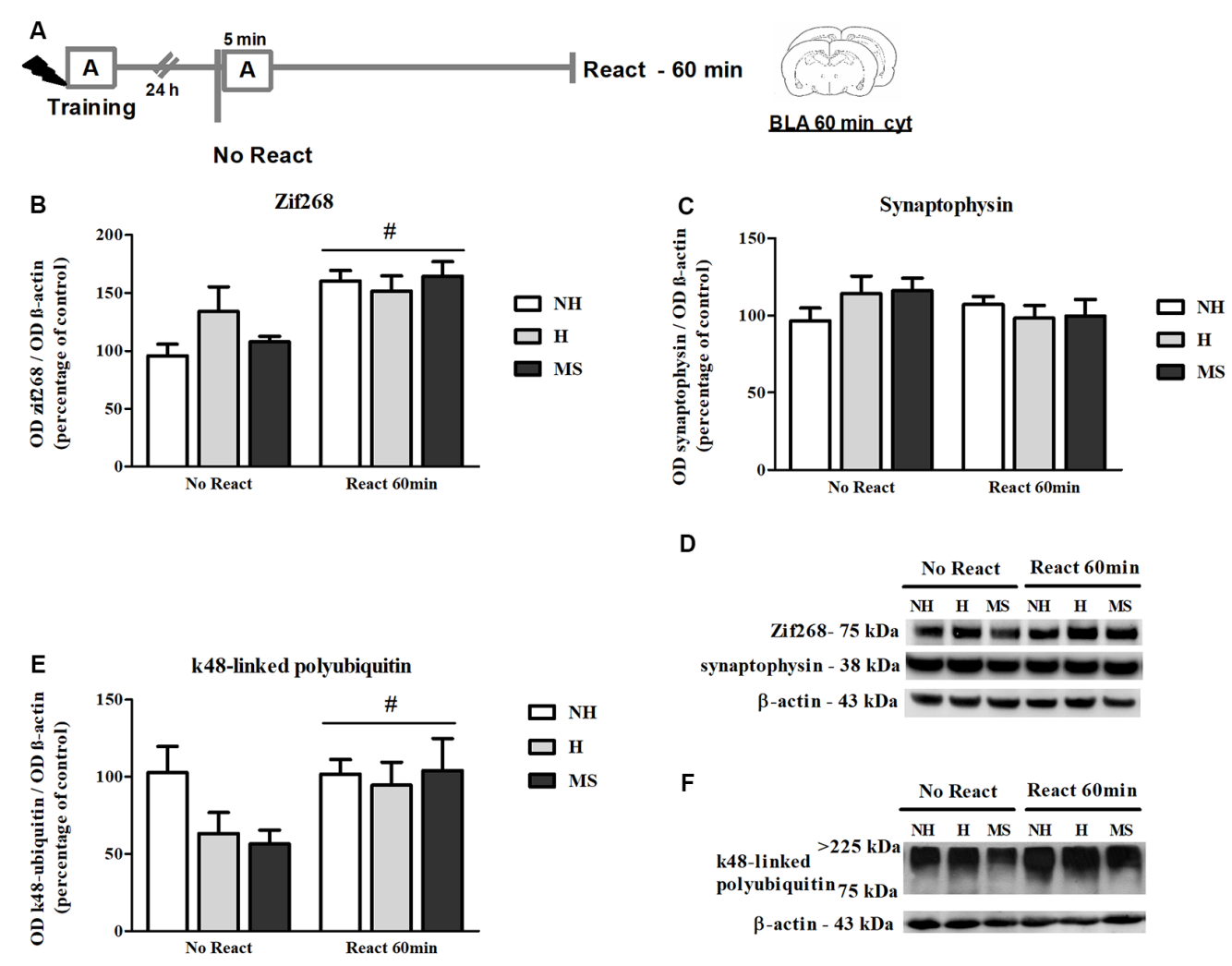

FIGURE 4 | Zif268, synaptophysin and k48-linked polyubiquitinated proteins immunocontent in the basolateral amygdala complex (BLA) cytosolic fraction (cyt) of adult male rats that were non-handled $(\mathrm{NH})$ or subjected to handling $(\mathrm{H})$ or maternal separation (MS) in the neonatal period, 60 min after Reactivation (React) compared to trained animals that were not re-exposed to the training context (No React). Memory reactivation induced a significant increase in Zif268 and polyubiquitinated proteins in the BLA cyt of all groups. (A) Schematic diagram of the experimental design; (B) Zif268; (C) synaptophysin; (D) representative Western blot bands; (E) k48-linked polyubiquitin proteins; (F) representative Western blot bands. Data are expressed as mean \pm SEM. $n=5-8 /$ group. 2W-ANOVA was used for statistical analyses; ${ }^{\#} p<0.05$ (main effect of reactivation). Statistics results are presented in detail in subsections "Zif268 Levels Increase in the BLA, 60 min After Aversive Memory Reactivation," "Memory Reactivation Induces Changes in Receptor Composition at the BLA Synapses" and "Synaptic NMDA and GABA $R$ Subunits Were not Changed by Memory Reactivation in the dHc."

\section{Neonatal Interventions Change ERK 1/2 Activation in the $\mathrm{dHc}, 15 \mathrm{~min}$ After Aversive Memory Reactivation}

ERK $1 / 2$ levels, as well as its activation by phosphorylation, were also studied in the $\mathrm{dHc}, 15 \mathrm{~min}$ post-reactivation (Figure 7A).

A significant interaction was found for ERK $1 / 2$ levels in this brain region $\left(F_{(2,31)}=3.905, p=0.031,2 \mathrm{w}\right.$-ANOVA; Figures $7 \mathbf{B}, \mathbf{F})$ but no significant main effects were found (neonatal intervention: $F_{(2,31)}=0.059, p=0.942$; reactivation: $F_{(2,31)}=2.142, p=0.153 ; 2 \mathrm{w}$-ANOVA). Tukey post hoc analysis revealed no significant differences between groups $(p>0.05)$. Still, the significant interaction between neonatal intervention and reactivation allows us to infer that early after memory reactivation, total ERK $1 / 2$ appears to decrease in $\mathrm{H}$ and MS, but increase in $\mathrm{NH}$ animals. Phosphorylated ERK 1/2 (pERK 1/2) levels were lower in MS animals, independently of reactivation $\left(F_{(2,31)}=3.589, p=0.040 ; 2 \mathrm{w}\right.$-ANOVA, main effect of neonatal intervention; Figures 7C,F); no interaction $\left(F_{(2,31)}=0.926, p=0.407 ; 2 \mathrm{w}\right.$-ANOVA $)$ or main effect of reactivation $\left(F_{(1,31)}=1.697, p=0.202 ; 2 \mathrm{w}\right.$-ANOVA) were found. A ratio of pERK 1/2 per total ERK 1/2 levels was calculated to evaluate changes in the relative phosphorylation status of ERK 1/2. A significant interaction was found for this ratio $\left(F_{(2,31)}=4.590, p=0.018,2 \mathrm{w}\right.$-ANOVA; Figures $\left.7 D, F\right)$ : Tukey post hoc test showed that cytosolic ERK $1 / 2$ activation levels were lower in the $\mathrm{dHc}$ of MS No React rats, compared to NH No React $(p=0.049)$ and H React $(p=0.030)$; but MS React animals were not different from other React groups (vs. NH React $-p=0.977$; vs. H React $-p=0.994$ ), which reveals a great increase in ERK $1 / 2$ phosphorylation at this time point, when $\mathrm{NH}$ animals already stabilized this process (NH No React vs. NH React- $p=0.630$ ). No main effects of neonatal intervention $\left(F_{(2,31)}=1.596, p=0.219 ; 2 \mathrm{w}\right.$-ANOVA) or reactivation $\left(F_{(1,31)}=2.426, p=0.130 ; 2 \mathrm{w}\right.$-ANOVA $)$ were found for this variable.

Increases in Zif268 immunocontent in hippocampal areas have been reported as early as $15 \mathrm{~min}$ post-reactivation (Besnard et al., 2014). Here, we did not find any significant differences in Zif268 levels at this time point (Figures 7E,F; interaction: $F_{(2,31)}=0.924, p=0.407$; neonatal intervention: $F_{(2,31)}=0.547, p=0.584$; reactivation: $F_{(1,31)}=0.154$, 

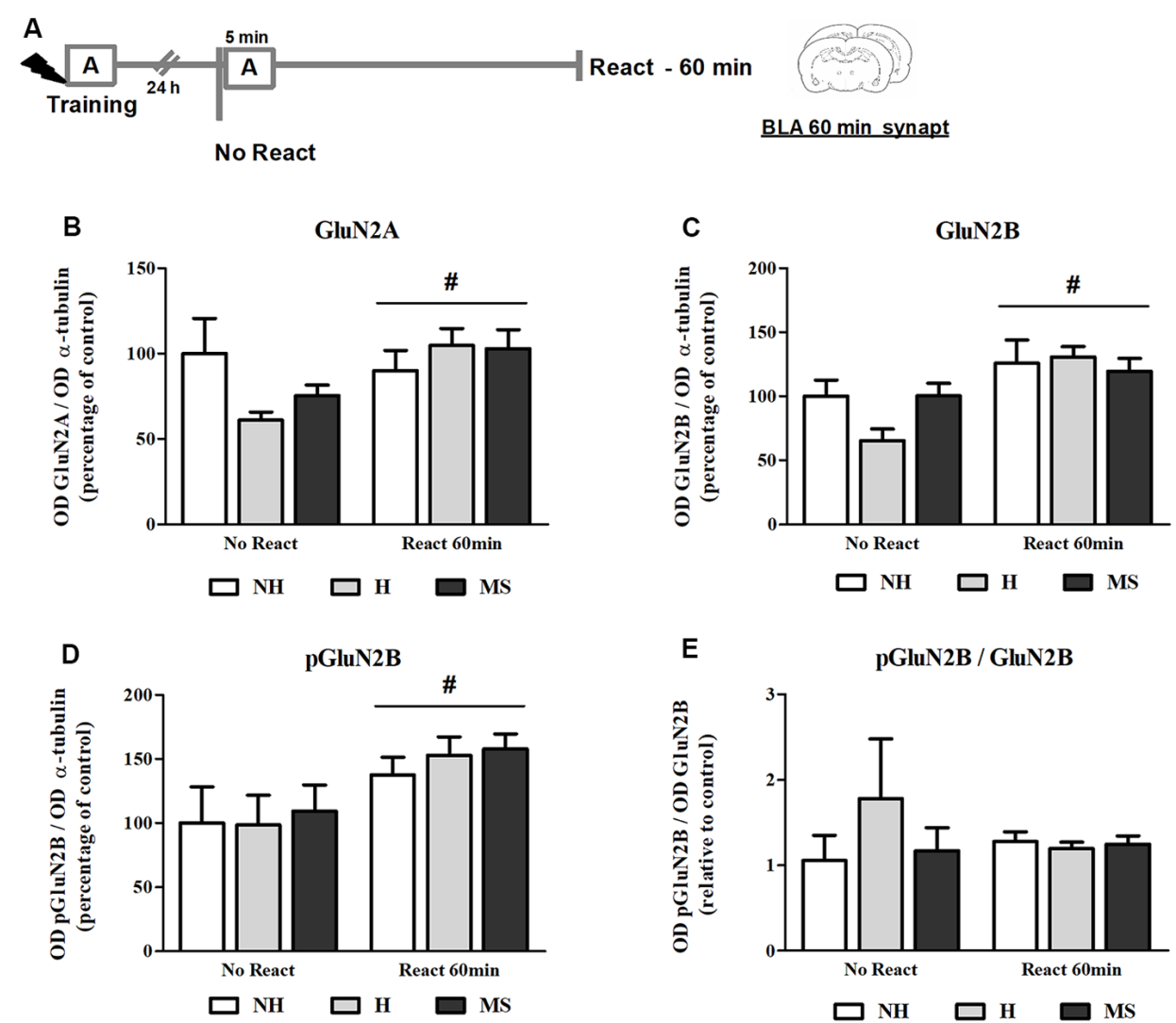

E
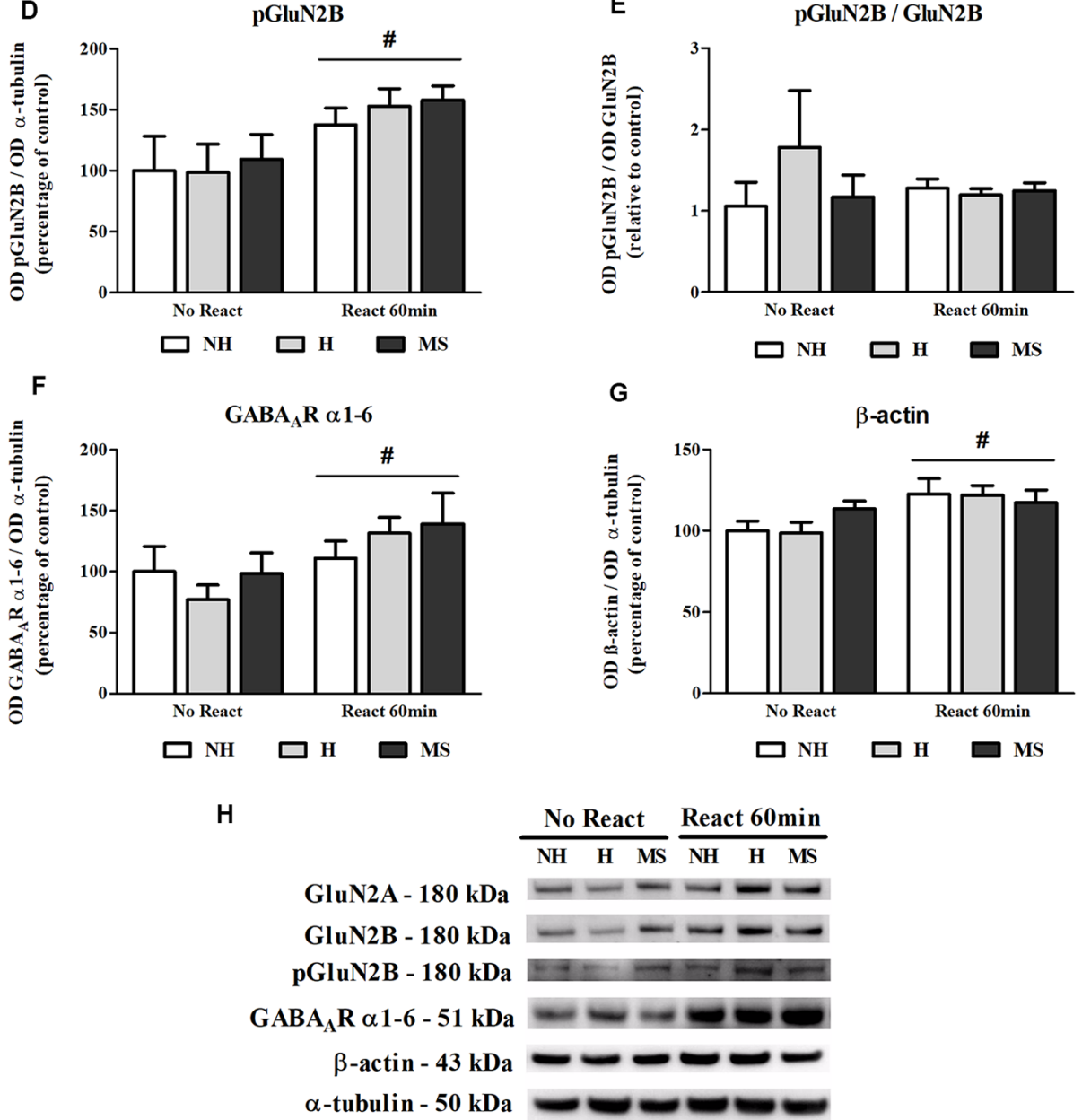

FIGURE 5 | NMDA receptor (NMDAR) subunits GluN2A and GluN2B (total and phosphorylated), GABA $\mathrm{R} \alpha 1-6$ subunits and $\beta$-actin immunocontent in the basolateral amygdala complex (BLA) synaptosome membrane fraction (synapt) of adult male rats that were non-handled $(\mathrm{NH})$ or subjected to handling $(\mathrm{H})$ or maternal separation (MS) in the neonatal period, 60 min after Reactivation (React) compared to trained animals that were not re-exposed to the training context (No React). Memory reactivation induced a significant increase in all receptor subunits and also $\beta$-actin in the BLA synapt of all groups. (A) Schematic diagram of the experimental design; (B) GluN2A; (C) GluN2B; (D) pGluN2B; (E) calculated ratio of pGluN2B per GluN2B immunocontent; (F) GABA R $\alpha 1-6$ subunits; (G) $\beta$-actin; (H) representative Western blot bands. Data are expressed as mean \pm SEM. $n=5-7 /$ group. 2 w-ANOVA was used for statistical analyses. ${ }^{\#} p<0.05$ (main effect of reactivation). Statistics results are presented in detail in subsection "Memory Reactivation Induces Changes in Receptor Composition at the BLA Synapses." 
A

BLA cyt - naïve



B

GluN2A

c

GluN2B

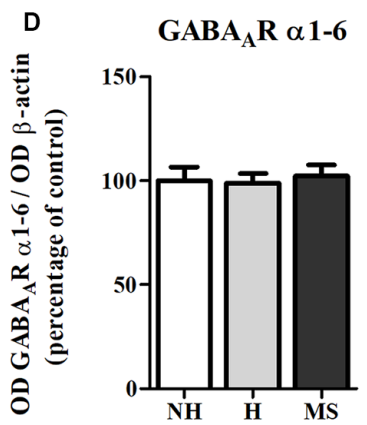

E

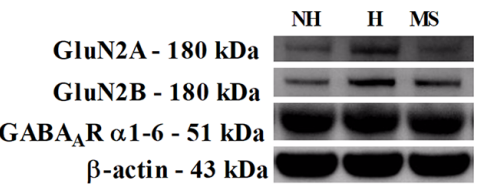

FIGURE 6 | NMDAR subunits GluN2A and GluN2B and GABA $A_{A} R \alpha 1-6$ subunits immunocontent in the basolateral amygdala complex (BLA) cytosolic fraction (cyt) of adult male rats that were non-handled $(\mathrm{NH})$ or subjected to handling $(\mathrm{H})$ or maternal separation $(\mathrm{MS})$ in the neonatal period. (A) Schematic diagram of the experimental design; (B) GluN2A; (C) GluN2B; (D) GABA $A_{A}$ a 1-6 subunits; (E) representative Western blot bands. Data are expressed as mean \pm SEM. $n=6-8$ /group. 1w-ANOVA was used for statistical analyses. ${ }^{*} p<0.05$. Statistics results are presented in detail in subsection "Memory Reactivation Induces Changes in Receptor Composition at the BLA Synapses."

$p=0.697 ; 2 \mathrm{w}$-ANOVA). The lack of a significant effect may be attributed to the lower sensitivity of the Western blot technique compared to immunohistochemistry, which was used in the aforementioned study.

\section{Zif268 Levels Increase in the dHc of NH, but Not H or MS, 60 min After Aversive Memory Reactivation}

Zif268 levels steadily increase in dentate gyrus during the reconsolidation window (Besnard et al., 2014). Hence, we also evaluated Zif268 immunocontent at $60 \mathrm{~min}$ post-reactivation (Figures 8A-C). A significant interaction was found $\left(F_{(2,29)}=5.361, p=0.010 ; 2 \mathrm{w}\right.$-ANOVA $)$; Tukey post hoc showed that memory reactivation in $\mathrm{NH}$ induced a significant increase in the immunocontent of this transcription factor, compared to NH No React $(p=0.001)$, H No React $(p=0.042)$, H React $(p=0.005)$ and MS No React $(p=0.011)$. React H and MS were not different from their respective No React controls ( $\mathrm{H}: p=1.000$; MS: $p=0.558)$. A significant effect of Reactivation was also encountered $\left(F_{(1,29)}=12.554, p=0.001 ; 2 \mathrm{w}\right.$ - ANOVA), but there was no significant effect of neonatal intervention on this variable $\left(F_{(2,29)}=0.690, p=0.509 ; 2 \mathrm{w}\right.$ - ANOVA).

\section{Synaptic NMDA and GABA $R$ Subunits Were Not Changed by Memory Reactivation in the $\mathrm{dHc}$}

NMDAR subunits GluN2A and GluN2B and $\alpha 1-6$ subunits of the $\mathrm{GABA}_{\mathrm{A}} \mathrm{R}$ were also measured in the $\mathrm{dHc}$ synapt fraction, 60 min post-reactivation (Figure 9A).
No significant changes were found in the immunocontent of subunits GluN2A (interaction: $F_{(2,30)}=0.679, p=0.515$; neonatal intervention: $F_{(2,30)}=0.395, p=0.677$; reactivation: $F_{(1,30)}=0.895, p=0.352,2 \mathrm{w}$-ANOVA; Figures 9B,E) or GluN2B (interaction: $F_{(2,30)}=0.508, p=0.607$; neonatal intervention: $F_{(2,30)}=1.144, p=0.332$; reactivation: $F_{(1,30)}=1.604, p=0.215$, $2 \mathrm{w}$-ANOVA; Figures 9C,E). For $\mathrm{GABA}_{\mathrm{A}} \mathrm{R} \alpha 1-6$ subunits, a trend towards a main effect of reactivation was found $\left(F_{(1,30)}=3.074, p=0.090 ; 2 \mathrm{w}\right.$-ANOVA; Figures 9D,E), but no significant interaction $\left(F_{(2,30)}=0.148, p=0.863 ; 2 \mathrm{~W}\right.$ ANOVA) or main effect of neonatal intervention were detected $\left(F_{(2,30)}=0.471, p=0.629 ; 2 \mathrm{w}\right.$-ANOVA $)$, which as mentioned before, suggests no significant differences in $\mathrm{GABA}_{\mathrm{A}} \mathrm{R}$ content at dHc synapses.

As in the BLA, no significant interaction $\left(F_{(2,30)}=0.078\right.$, $p=0.925 ; 2 \mathrm{w}$-ANOVA) or main effects (neonatal intervention: $F_{(2,30)}=0.718, p=0.496$; reactivation: $F_{(1,30)}=0.045, p=0.833$; $2 \mathrm{w}$-ANOVA) were found for the GluN2A/GluN2B synaptic ratio (data not shown).

\section{k48-Linked Polyubiquitin Levels Were Increased by Reactivation in the BLA, but Not in dHc}

k48-linked polyubiquitination was assessed 60 min after memory reactivation since it has been demonstrated that at this time point, retrieval-induced UPS activation significantly increases both in the hippocampus and amygdala (Lee et al., 2008; Jarome et al., 2011). A significant increase was detected in Reactivation animals in the BLA (Figures 4E,F; $F_{(1,31)}=5.041, p=0.032$, 


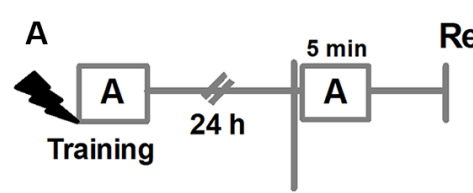

No React

B

ERK 1/2

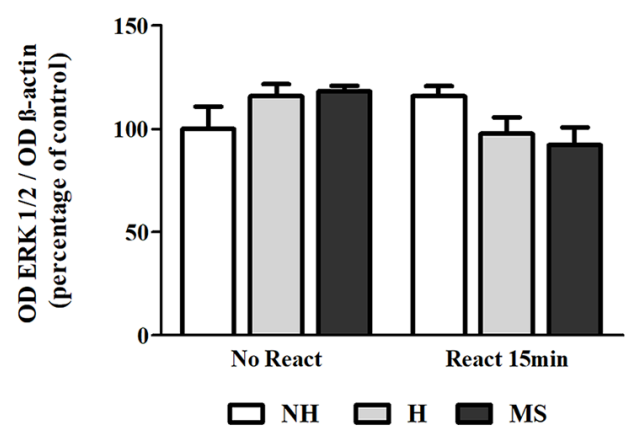

D

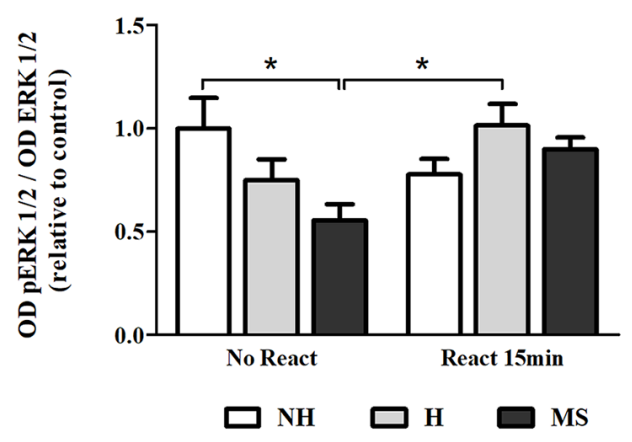

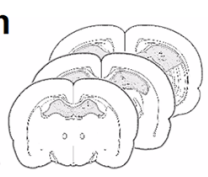

dHc $15 \mathrm{~min}$ cyt
C

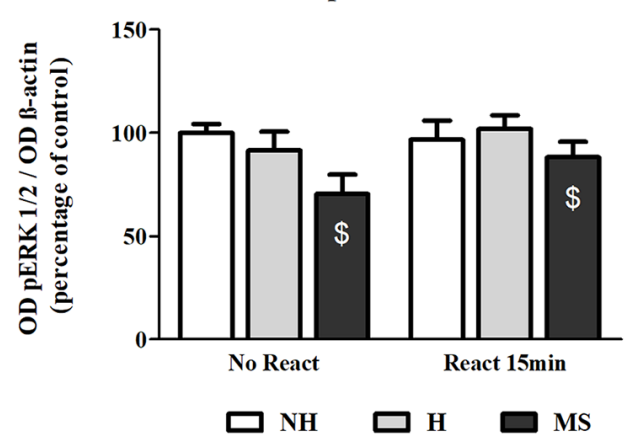

$E$

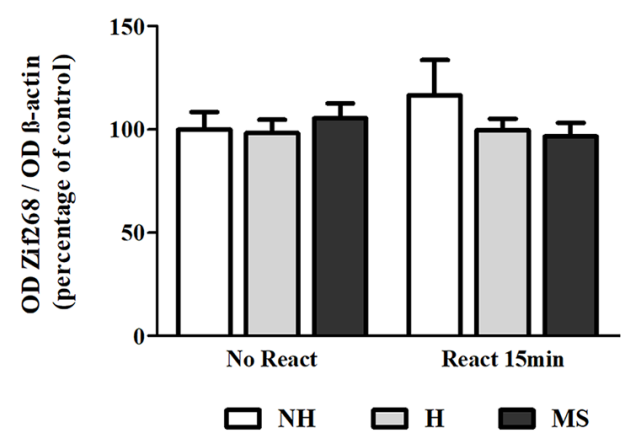

$\mathbf{F}$

ERK 1/2 - 42-44 kDa

No React React 15min

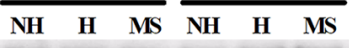

pERK 1/2 - 42-44 kDa

Zif268- 75 kDa

$\beta$-actin - 43 kDa

FIGURE 7 | ERK 1/2, pERK 1/2 and Zif268 immunocontent in the dorsal hippocampus (dHc) cytosolic fraction (cyt) of adult male rats that were non-handled (NH) or subjected to handling $(\mathrm{H})$ or maternal separation $(\mathrm{MS})$ in the neonatal period, 15 min after Reactivation (React) compared to trained animals that were not re-exposed to the training context (No React). Activation of ERK 1/2 in the dHc appears to be delayed, particularly in MS rats. (A) Schematic diagram of the experimental design; (B) ERK 1/2; (C) pERK 1/2; (D) calculated ratio of pERK 1/2 per ERK 1/2 immunocontent; (E) Zif268; (F) representative Western blot bands. Data are expressed as mean \pm SEM. $n=5-8$ /group. 2 w-ANOVA was used for statistical analyses. ${ }^{*} p<0.05 ;{ }^{\$} p<0.05$ (main effect of neonatal intervention). Statistics results are presented in detail in subsection "Neonatal Interventions Change ERK 1/2 Activation in the dHc, 15 min After Aversive Memory Reactivation."

2w-ANOVA, main effect of Reactivation, no interaction). In the dHc, no interaction or main effects were detected (Figures 8D,E; $p>0.05,2 \mathrm{w}$-ANOVA). k48-linked polyubiquitination is an indirect measure of protein degradation, which in the amygdala has been successfully correlated with memory destabilization
(Jarome et al., 2011, 2016; Jarome and Helmstetter, 2014), but in the hippocampus, more direct techniques have been used to link protein degradation to retrieval-induced memory destabilization, including UPS inhibition (Artinian et al., 2008; Lee et al., 2008; Sol Fustiñana et al., 2014) and sample purification using the $26 \mathrm{~S}$ 


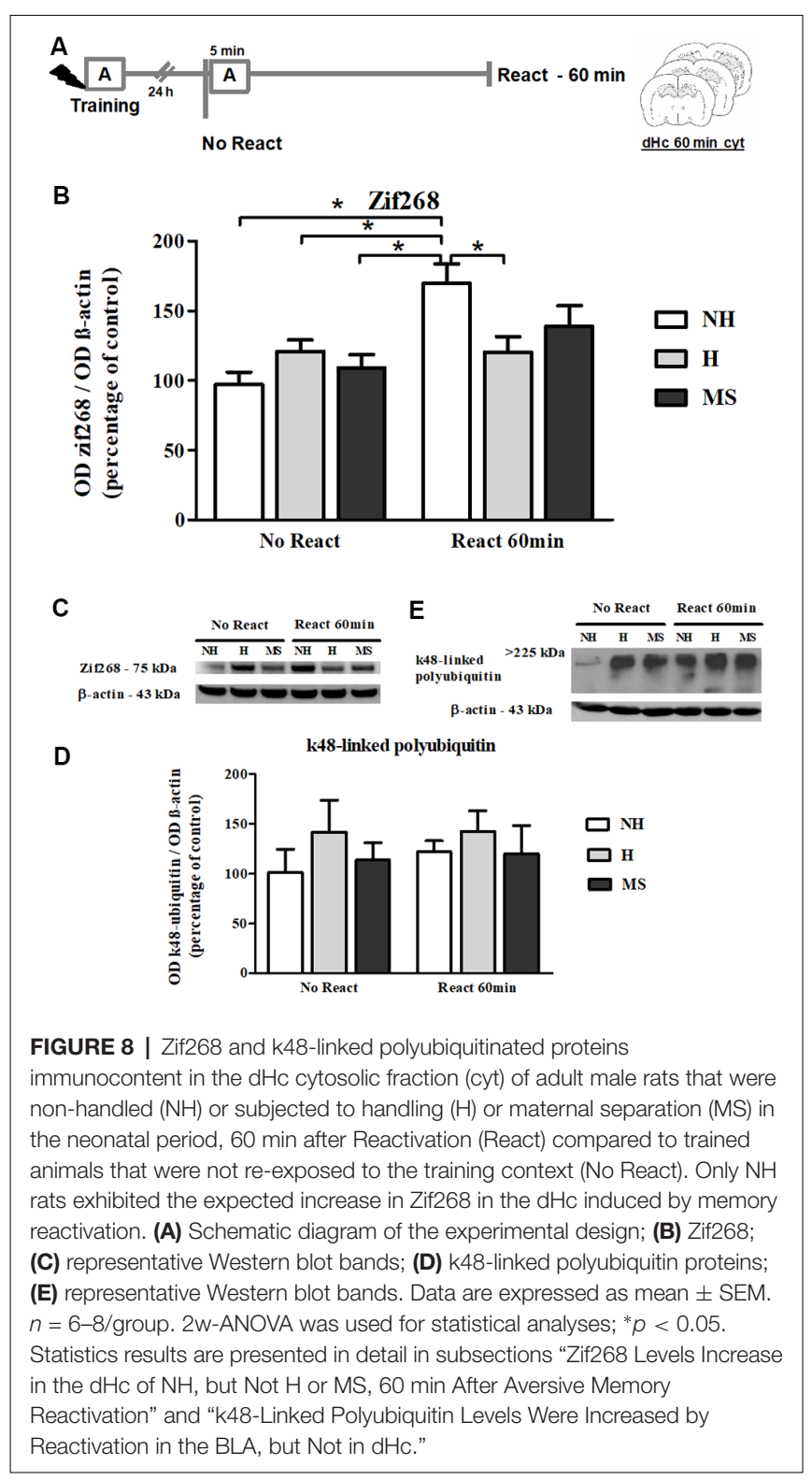

proteasome subunit S5a before Western blot experiments (Lee et al., 2008), so it is possible that the method used here may lack sensitivity to detect hippocampal protein degradation.

\section{DISCUSSION}

Neonatal interventions change memory consolidation and retrieval (Kosten et al., 2012). Here, we showed that they also affect aversive memory reconsolidation. Unlike $\mathrm{NH}$ rats, $\mathrm{H}$ and MS animals showed resistance to reconsolidation disruption by mdz, a GABAergic drug, administered after memory retrieval. At a molecular level, both groups showed changes similar to $\mathrm{NH}$ animals in the BLA after memory reactivation, but their dHc appeared to respond differently. Furthermore, behavioral expression of the aversive memory was very different in the two groups: while $\mathrm{H}$ animals exhibited significant less freezing to the conditioned context presentation, MS rats generalized their fear response to a new and unconditioned context.

Decreased retrieval-induced freezing shown by $\mathrm{H}$ rats is consistent with reduced emotional reactivity and the proposed increased inhibitory control of the amygdala by the medial pre-frontal cortex (Stevenson et al., 2008), since amygdalar nuclei are involved in fear expression through its excitatory projections to the periaqueductal gray-PAG (Gross and Canteras, 2012). It could also be the result of cortical or hippocampal dysfunction and consequently impairments in context recognition. However, $\mathrm{H}$ males perform normally in memory tasks that are associated with neutral or appetitive stimuli (Kosten et al., 2007; Noschang et al., 2010, 2012) so the cognitive impairment hypothesis has been disregarded (Kosten et al., 2012). Furthermore, re-exposure to the aversive context is stressful for $\mathrm{H}$ animals, as can be seen by corticosterone secretion $15 \mathrm{~min}$ post exposure (CoutoPereira et al., 2016), pointing that these animals are perfectly able to recognize the danger and the associated context. Besides, several studies have pointed out that $\mathrm{H}$ animals exhibit a behavioral and neurochemical profile of resilience to stress, when adults (Plotsky et al., 2005; Meaney et al., 2013). Together with the low freezing shown here, it is reasonable to assume that the fear memory acquired by $\mathrm{H}$ animals may be less emotionally aversive, which may have affected its consolidation and, consequently, reconsolidation.

Aversive memory generalization is a less investigated type of memory impairment, which can be observed when animals freeze to unspecific cues. This trait has often been associated with PTSD, both in animal models and clinical studies (Xu and Südhof, 2013; Thome et al., 2018). Fear generalization to a new context has already been shown in the adult neonatal isolation offspring and was attributed to enhanced theta synchronization in the hippocampus-amygdala-cortical loop during REM sleep by the authors (Sampath et al., 2014). MS rats in our study exhibited higher freezing in the new context (B), compared to $\mathrm{H}$, which suggests fear memory generalization (Winocur et al., 2009; Yang et al., 2011; Sampath et al., 2014). Novelty anxiety impact on this result was discarded by showing that before receiving footshocks, MS animals did not freeze more than the other groups in an unfamiliar environment. A previous study from our group has shown that a strong aversive experience subsequently impairs spatial memory in MS rats (Diehl et al., 2012), which suggests that stressful events may impair MS hippocampal function, causing the animals to have lower ability to discriminate contextual cues, a feature that requires the hippocampus (Fanselow and Dong, 2010), and setting them to exhibit a PTSD-like phenotype (Finsterwald et al., 2015). The absence of behavioral differences comparing MS rats to the other groups before the stressful event (footshock), followed by fear generalization after being exposed to a stressor is in accordance with the second-hit hypothesis (Daskalakis et al., 2013; Finsterwald et al., 2015).

Since $\mathrm{H}$ and MS rats showed resistance to $\mathrm{mdz}$ interfering effect on memory reconsolidation, we further investigated the molecular pathways involved with this process in the BLA and $\mathrm{dHc}$. Both these brain regions are involved with the processing of contextual aversive memories, as pointed 

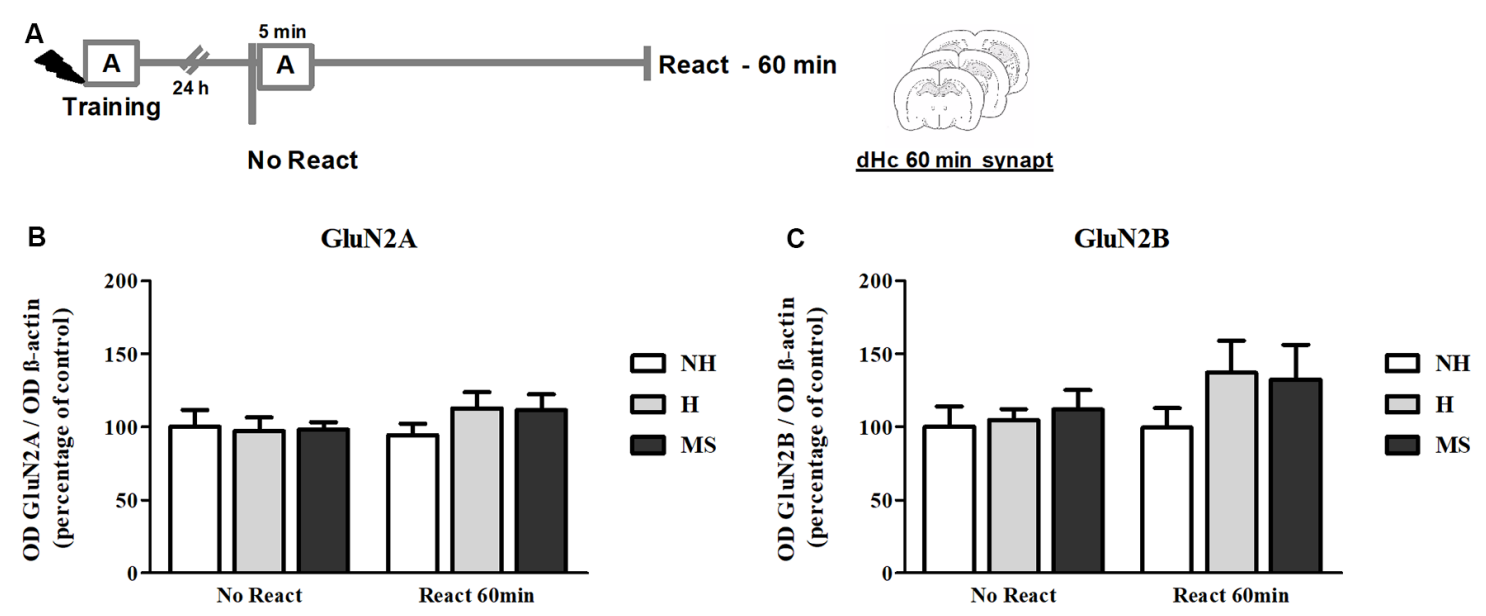

D

$\mathrm{GABA}_{\mathbf{A}} \mathrm{R} \alpha 1-6$

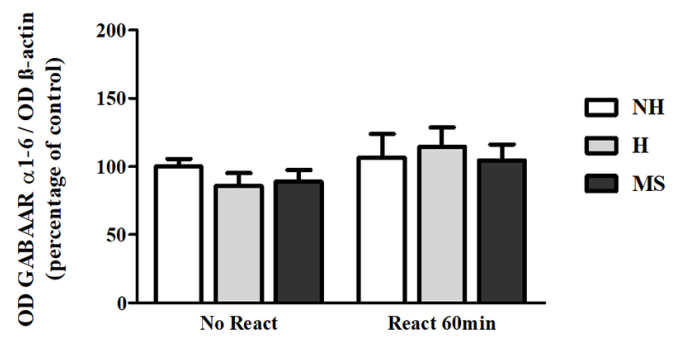

E



FIGURE 9 | NMDAR subunits GluN2A and GluN2B and GABA $R \alpha 1-6$ subunits immunocontent in the dHc synaptosome membrane fraction (synapt) of adult male rats that were non-handled $(\mathrm{NH})$ or subjected to handling $(\mathrm{H})$ or maternal separation $(\mathrm{MS})$ in the neonatal period, 60 min after Reactivation (React) compared to trained animals that were not re-exposed to the training context (No React). No significant changes in N-Methyl-D-aspartate (NMDA) or GABA $\mathrm{A}_{\mathrm{A}}$ subunit composition were found in the dHc. (A) Schematic diagram of the experimental design; (B) GluN2A; (C) GluN2B; (D) GABA $R$ R1-6 subunits; (E) representative Western blot bands. Data are expressed as mean \pm SEM. $n=5-7 /$ group. 2 w-ANOVA was used for statistical analyses. Statistics results are presented in detail in subsection "Synaptic NMDA and GABA $\mathrm{R}$ Subunits Were not Changed by Memory Reactivation in the dHc."

earlier (Phillips and LeDoux, 1992), but operate in an unequal manner (Cammarota et al., 2008). ERK 1/2 signaling has been differently implicated in the molecular mechanism of memory destabilization and reconsolidation in the $\mathrm{dHc}$ and BLA (Tronson and Taylor, 2007; Besnard et al., 2013, 2014). Here, we reported that $15 \mathrm{~min}$ after reactivation, ERK $1 / 2$ activation was altered in the $\mathrm{dHc}$, but not in the BLA, possibly because in the latter, increased pERK 1/2 levels have been reported only $30 \mathrm{~min}$ after reactivation (Besnard et al., 2014). Results presented here refer to cytosolic protein levels. Upon activation, pERK $1 / 2$ translocates to the nucleus, where it phosphorylates downstream transcription factors (Treisman, 1996), which has been shown to be essential for LTP in the dentate gyrus (Davis et al., 2000). Hence, it is reasonable to hypothesize that at the time point analyzed here, in $\mathrm{NH}$ animals, activated ERK $1 / 2$ could have already migrated to the nucleus, causing the observed lower levels in the cyt fraction, while in MS rats, this process was still beginning since differences in absolute and relative pERK $1 / 2$ levels were found in these animals. To further elucidate this hypothesis, it would be interesting to analyze the activation of its nuclear substrates, such as the cAMP response element-binding protein (CREB) or Elk-1.
Zif268, an inducible transcription factor which expression is also regulated by ERK 1/2 signaling (Davis et al., 2000; Tronson and Taylor, 2007), is necessary for reconsolidation (Bozon et al., 2003; Lee et al., 2004; Besnard et al., 2013), and has been repeatedly found increased in the hippocampus (Hall et al., 2001; Besnard et al., 2014) and amygdala (Hall et al., 2001; Maddox et al., 2011; Espejo et al., 2016), during contextual memory reconsolidation. We reported here a significant increase in Zif268, 60 min after the reactivation session in the BLA of all animals, independently of the neonatal treatment. In contrast, in the $\mathrm{dHc}$, only $\mathrm{NH}$ rats showed a significant increase in Zif268 levels, but not $\mathrm{H}$ or MS animals.

Increases in GluN2A, GluN2B and its phosphorylated form were also observed in the BLA synap fraction, $60 \mathrm{~min}$ after reactivation; whether these changes result from increased synthesis or increased trafficking of receptor subunits to the synapse or both remains unanswered; it does not seem to result from decreased endocytosis, since no changes in the ratio of pGluN2B to total GluN2B were found. Interestingly, an increase in $\mathrm{GABA}_{\mathrm{A}} \mathrm{R} \alpha 1-6$ subunits was also found in the BLA after memory reactivation, which to our knowledge, had not been reported previously. Structural and functional changes 
in postsynaptic terminals of MS rats BLA have been reported, including dendrite hypertrophy and increased spine density (Koe et al., 2016), as well as increased firing rate in the BLA in vivo, when a $\mathrm{GABA}_{\mathrm{A}} \mathrm{R}$ inverse agonist was administered (Stevenson et al., 2008), so we analyzed synaptophysin levels in the BLA. In the present study, no significant differences were found concerning synaptophysin in the BLA, which is in accordance with a previous study in MS rats of similar age (Andersen and Teicher, 2004); this suggests that there are no marked changes in presynaptic terminals in the BLA of $\mathrm{NH}$, $\mathrm{H}$ and MS adult rats. Still, naïve $\mathrm{H}$ animals had higher levels of GluN2A compared to $\mathrm{NH}$ in the BLA, which appeared to level with controls after consolidation. Receptor composition reorganization is part of the consolidation plasticity process (Kopp et al., 2007), thus it is possible that consolidation in $\mathrm{H}$ occurred differently at the BLA, thus subsequently affecting reconsolidation. This hypothesis deserves further investigation, as it may lead to the elucidation of another aspect of resilience induced by early handling.

In the $\mathrm{dHc}$ synapt, no changes in NMDAR or $\mathrm{GABA}_{\mathrm{A}} \mathrm{R}$ subunits were found. NMDARs in the $\mathrm{dHc}$ are crucial for aversive memory reconsolidation; intra- $\mathrm{dHc}$ administration of an NMDA antagonist prevented the reconsolidation-induced update of an aversive memory (Crestani et al., 2015; Haubrich et al., 2015) and NMDA subunit composition determined destabilization and restabilization processes (Milton et al., 2013). However, changes in NMDAR activity unrelated to subunit immunocontent cannot be ruled out by our findings.

Memory reactivation by exposure to contextual cues brings the trace back to a labile state which has been attributed to protein degradation via UPS (Lee et al., 2008; Jarome et al., 2011, 2016; Sol Fustiñana et al., 2014). Retrieval-induced UPS activation depends on NMDAR-mediated calcium influx and subsequent activation of CaMKII, in the amygdala (Jarome et al., 2011, 2016). A significant increase in the levels of polyubiquitinated $\mathrm{k} 48$-linked proteins was found $60 \mathrm{~min}$ after retrieval, in the BLA of all groups studied here. Ubiquitin polymeric chains linked through lysine residue 48 are involved with targeting proteins for degradation by the UPS (Mattiroli and Sixma, 2014) and the amount of k48-polyubiquitinated proteins detected in the amygdala have been shown to be correlated with proteasome activity in the amygdala (Jarome et al., 2011). This suggests that memory destabilization occurred in the BLA of all groups. The involvement of protein degradation in memory destabilization has been less studied in the hippocampus; while, like in the BLA, it has been suggested as the mechanism underlying memory destabilization (Lee et al., 2008), inhibition of the UPS in hippocampal areas produced the same effects as protein synthesis inhibitors in spatial memory (Artinian et al., 2008), raising some questions regarding the role and time of hippocampal protein degradation in memory reconsolidation (Jarome and Helmstetter, 2014). Here, we could not detect any significant changes in k48-linked polyubiquitin levels in the $\mathrm{dHc}$, which could also be due to the sensitivity of the methodology used.

So, why did $\mathrm{H}$ and MS animals fail to change their behavioral responses to the aversive context after receiving the GABAergic drug $\mathrm{mdz}$, following memory retrieval? The simplest explanation is that the GABAergic system is altered in these animals so that the drug does not achieve the same effect as in $\mathrm{NH}$ rats. In accordance, stressful experiences in rats can change GABAergic transmission in the BLA afferents and internal circuits (Caldji et al., 2000; RodríguezManzanares et al., 2005; Stevenson et al., 2008) and may decrease the effect of $\mathrm{mdz}$ on memory reconsolidation (Ortiz et al., 2015). In adult $\mathrm{H}$ males, increased binding of a non-BZD $\mathrm{GABA}_{\mathrm{A}} \mathrm{R}$ agonist was reported in amygdala nuclei, compared to $\mathrm{NH}$ and MS (Caldji et al., 2000). In the dentate gyrus of adult animals that were exposed to a single MS event, decreased neuronal $\mathrm{GABA}_{\mathrm{A}} \mathrm{R}$-mediated inhibitory currents were found, as well as changes in $\alpha$ subunits transcription (Hsu et al., 2003). Our findings suggest no differences in the total $\mathrm{GABA}_{\mathrm{A}} \mathrm{R}$ density at the synapses of $\mathrm{NH}, \mathrm{H}$ and MS rats; furthermore, if altered GABAergic transmission was the main explanation, at least $\mathrm{H}$ rats would be expected to respond to $\mathrm{mdz}$ treatment, since evidences point to an increase in overall GABAergic function in their amygdala. The possibility of a floor effect is not excluded, since $\mathrm{H}$ rats exhibited low freezing in all sessions, equivalent to $\mathrm{NH}$ freezing after memory impairment by mdz. Hence, it would be interesting to test reconsolidation impairment in these animals in response to a different drug.

However, more relevant to answer this question is that our results suggest that the BLA of $\mathrm{H}$ and $\mathrm{MS}$ rats underwent a process very similar to what is currently believed to occur during reconsolidation, in terms of Zif268 upregulation, GluN2B subunit and actin increased density at the synaptic membrane and increased protein polyubiquitination, but not their $\mathrm{dHc}$, which showed relevant differences compared to $\mathrm{NH}$ animals, particularly regarding the delay in ERK $1 / 2$ activation and the absence of Zif268 induction.

Most studies on reconsolidation boundary conditions have identified impairments in the retrieval-reconsolidation process at the BLA (Wang et al., 2009; Ortiz et al., 2015; Espejo et al., 2016, 2017). In fact, downregulation of GluN2B (Wang et al., 2009) or increased GluN2A/GluN2B ratio (Holehonnur et al., 2016) in the BLA has been proposed to be the mechanism that prevents strong memories from becoming labile and undergoing reconsolidation. Here, no differences were found regarding the ratio of the two subunits. Also, Zif268 increased expression has been shown to be dependent on NMDARs activity (Malkani and Rosen, 2001; Mokin and Keifer, 2005) and H and MS animals had an increase in the levels of this transcription factor. It is plausible to think that despite the proposed differences in basal and stress-induced excitability of the amygdala resulting from different early experiences (Stevenson et al., 2008; Koe et al., 2016), the BLA of NH, H and MS appears to similarly engage in reconsolidation after retrieval of a contextual fear memory. Hence, our results point to the hippocampus or to its interaction with the amygdala as the possible origin of their differences in memory reconsolidation. In fact, in another study in which rats were subjected to a strong and prolonged stress as adults, differences in the hippocampal response were also found in memory reconsolidation resistance (Hoffman et al., 2015). 
The $\mathrm{dHc}$ is responsible for detecting novelty in the context where memory is retrieved (Rossato et al., 2007) and a mismatch between the expectation the animal has when it is exposed to the context and reality is a condition that has been shown to be necessary to trigger reconsolidation (Pedreira et al., 2004; Agustina López et al., 2016). Futhermore, hippocampal plasticity mechanisms have been implicated in memory update after retrieval (de Oliveira Alvares et al., 2013; Crestani et al., 2015; Haubrich et al., 2015) and blocking protein synthesis in the $\mathrm{dHc}$ after memory retrieval impaired subsequent freezing to multiple contextual cues, while the same procedure in the BLA only impaired freezing to an auditory cue (Yang et al., 2011). The BLA-dHc circuit presents a dual-dynamic interaction (Richter-Levin and Akirav, 2000) and orchestrated processing by the two structures in memory reconsolidation has been reported (Wang et al., 2009; Besnard et al., 2014), including enhanced theta synchronization in this circuit during retrieval (Seidenbecher et al., 2003; Narayanan et al., 2007). If impaired or delayed $\mathrm{dHc}$ plasticity was the mechanism responsible for the failure in memory update in $\mathrm{H}$ and MS rats, it could be the result of differential BLA modulation of $\mathrm{dHc}$ in $\mathrm{H}$ and MS rats or partial failure in enhancing theta synchronization between the two structures during reactivation. The apparent timeshift in dHc ERK 1/2 activation in $\mathrm{H}$ and MS rats supports this hypothesis. The hippocampus has been suggested as a central structure in PTSD (Maren et al., 2013; Abdallah et al., 2017) and aberrant context processing could, in fact, be a mechanism underlying PTSD (Liberzon and Abelson, 2016), possibly more important than amygdala hyperactivation (Diamond and Zoladz, 2015).

In summary, our results suggest that neonatal interventions in rodents are interesting models to study the mechanisms underlying resistance to reconsolidation; they also contribute to the study of dHc-BLA interaction during memory reconsolidation and to the idea that a fine synchrony between brain structures must occur for memory to be labilized; finally, understanding how early experiences, particularly MS, modulate fear memory reconsolidation in rodents may provide interesting insights on the neurobiological mechanisms of PTSD as well as new therapeutical approaches.

\section{REFERENCES}

Abdallah, C. G., Wrocklage, K. M., Averill, C. L., Akiki, T., Schweinsburg, B., Roy, A., et al. (2017). Anterior hippocampal dysconnectivity in posttraumatic stress disorder: a dimensional and multimodal approach. Transl. Psychiatry 7:e1045. doi: 10.1038/tp.2017.12

Agustina López, M., Jimena Santos, M., Cortasa, S., Fernández, R. S., Carbó Tano, M., and Pedreira, M. E. (2016). Different dimensions of the prediction error as a decisive factor for the triggering of the reconsolidation process. Neurobiol. Learn. Mem. 136, 210-219. doi: 10.1016/j.nlm.2016. 10.016

Akirav, I., and Maroun, M. (2013). Stress modulation of reconsolidation. Psychopharmacology 226, 747-761. doi: 10.1007/s00213-0122887-6

Andersen, S. L., and Teicher, M. H. (2004). Delayed effects of early stress on hippocampal development. Neuropsychopharmacology 29, 1988-1993. doi: $10.1038 /$ sj.npp. 1300528

\section{ETHICS STATEMENT}

This study was carried out in accordance with the recommendations of the Brazilian Law regarding the use of animals (Federal Law 11.794/2008) and the Guidelines for the Care and Use of Mammals in Neuroscience and Behavioral Research (National Research Council 2003). The protocol was approved by the institutional Research Ethics Committee: CEUA-UFRGS, under the number \#23844.

\section{AUTHOR CONTRIBUTIONS}

NC-P, CD, JQ and VM conceived and planned the experiments. NC-P, CLam, AV, CLaz and GK carried out the behavioral experiments. NC-P, CLam and PE performed sample preparation and biochemical experiments. NC-P, CLam, CD, JQ and VM contributed to the interpretation of the results. NC-P wrote the manuscript. All authors provided critical feedback on the manuscript.

\section{FUNDING}

This work was financially supported by Conselho Nacional de Desenvolvimento Científico e Tecnológico ( $\mathrm{CNPq}$ ), Instituto Nacional de Ciência e Tecnologia para Excitotoxicidade e Neuroproteção (INCTEN/CNPq \#465671/2014-4) and Coordenação de Aperfeiçoamento de Pessoal de Nível Superior (CAPES). $\mathrm{CNPq}$ and INCTEN/CNPq funding allowed the acquisition of reagents necessary for developing this work. CAPES provided scholarships for NC-P, CLam and AV.

\section{ACKNOWLEDGMENTS}

This work is part of the thesis presented by NC-P to obtain the $\mathrm{PhD}$ degree; the thesis can be accessed online. Partial results of this manuscript were presented at the 2018 International Conference on Learning and Memory, held in Huntington Beach, CA, USA. We wish to thank Ms Flávia Zacouteguy Boos for her participation in the inter-reliability assessment of freezing analyses.

Arnett, M. G., Pan, M. S., Doak, W., Cyr, P. E. P., Muglia, L. M., and Muglia, L. J. (2015). The role of glucocorticoid receptor-dependent activity in the amygdala central nucleus and reversibility of early-life stress programmed behavior. Transl. Psychiatry 5:e542. doi: 10.1038/tp.2015.35

Artinian, J., McGauran, A. M. T., De Jaeger, X., Mouledous, L., Frances, B., and Roullet, P. (2008). Protein degradation, as with protein synthesis, is required during not only long-term spatial memory consolidation but also reconsolidation. Eur. J. Neurosci. 27, 3009-3019. doi: 10.1111/j.1460-9568. 2008.06262.x

Ben-Mamou, C., Gamache, K., and Nader, K. (2006). NMDA receptors are critical for unleashing consolidated auditory fear memories. Nat. Neurosci. 9, 1237-1239. doi: 10.1038/nn1778

Besnard, A., Caboche, J., and Laroche, S. (2013). Recall and reconsolidation of contextual fear memory: differential control by ERK and Zif268 expression dosage. PLoS One 8:e72006. doi: 10.1371/journal.pone.0072006

Besnard, A., Laroche, S., and Caboche, J. (2014). Comparative dynamics of MAPK/ERK signalling components and immediate early genes in the 
hippocampus and amygdala following contextual fear conditioning and retrieval. Brain Struct. Funct. 219, 415-430. doi: 10.1007/s00429-013-0505-y

Blanchard, R. J., and Blanchard, D. C. (1969). Crouching as an index of fear. J. Comp. Physiol. Psychol. 67, 370-375. doi: 10.1037/h0026779

Bolton, J. L., Molet, J., Ivy, A., and Baram, T. Z. (2017). New insights into early-life stress and behavioral outcomes. Curr. Opin. Behav. Sci. 14, 133-139. doi: 10.1016/j.cobeha.2016.12.012

Bozon, B., Davis, S., and Laroche, S. (2003). A requirement for the immediate early gene zif268 in reconsolidation of recognition memory after retrieval. Neuron 40, 695-701. doi: 10.1016/s0896-6273(03)00674-3

Bustos, S. G., Giachero, M., Maldonado, H., and Molina, V. A. (2010). Previous stress attenuates the susceptibility to Midazolam's disruptive effect on fear memory reconsolidation: influence of pre-reactivation D-cycloserine administration. Neuropsychopharmacology 35, 1097-1108. doi: 10.1038/npp. 2009.215

Bustos, S. G., Maldonado, H., and Molina, V. A. (2006). Midazolam disrupts fear memory reconsolidation. Neuroscience 139, 831-842. doi: 10.1016/j. neuroscience.2005.12.064

Bustos, S. G., Maldonado, H., and Molina, V. A. (2009). Disruptive effect of midazolam on fear memory reconsolidation: decisive influence of reactivation time span and memory age. Neuropsychopharmacology 34, 446-457. doi: 10.1038/npp.2008.75

Caldji, C., Francis, D., Sharma, S., Plotsky, P. M., and Meaney, M. J. (2000). The effects of early rearing environment on the development of $\mathrm{GABA}_{\mathrm{A}}$ and central benzodiazepine receptor levels and novelty-induced fearfulness in the rat. Neuropsychopharmacology 22, 219-229. doi: 10.1016/s0893-133x(99) 00110-4

Cammarota, M., Bevilaqua, L. R., Rossato, J. I., Lima, R. H., Medina, J. H., and Izquierdo, I. (2008). Parallel memory processing by the CA1 region of the dorsal hippocampus and the basolateral amygdala. Proc. Natl. Acad. Sci. U S A 105, 10279-10284. doi: 10.1073/pnas.0805284105

Chen, B.-S., and Roche, K. W. (2007). Regulation of NMDA receptors by phosphorylation. Neuropharmacology 53, 362-368. doi: 10.1016/j.neuropharm. 2007.05.018

Couto-Pereira, N. S., Ferreira, C. F., Lampert, C., Arcego, D. M., Toniazzo, A. P., Bernardi, J. R., et al. (2016). Neonatal interventions differently affect maternal care quality and have sexually dimorphic developmental effects on corticosterone secretion. Int. J. Dev. Neurosci. 55, 72-81. doi: 10.1016/j. ijdevneu.2016.10.001

Crestani, A. P., Zacouteguy Boos, F., Haubrich, J., Ordoñez Sierra, R., Santana, F., Molina, J. M. D., et al. (2015). Memory reconsolidation may be disrupted by a distractor stimulus presented during reactivation. Sci. Rep. 5:13633. doi: 10.1038/srep13633

Daskalakis, N. P., Bagot, R. C., Parker, K. J., Vinkers, C. H., and de Kloet, E. R. (2013). The three-hit concept of vulnerability and resilience: toward understanding adaptation to early-life adversity outcome. Psychoneuroendocrinology 38, 1858-1873. doi: 10.1016/j.psyneuen.2013. 06.008

Daskalakis, N. P., De Kloet, E. R., Yehuda, R., Malaspina, D., and Kranz, T. M. (2015). Early life stress effects on glucocorticoid-BDNF interplay in the hippocampus. Front. Mol. Neurosci. 8:68. doi: 10.3389/fnmol.2015. 00068

Davis, S., Vanhoutte, P., Pagès, C., Caboche, J., and Laroche, S. (2000). The MAPK/ERK cascade targets both Elk-1 and cAMP response element-binding protein to control long-term potentiation-dependent gene expression in the dentate gyrus in vivo. J. Neurosci. 20, 4563-4572. doi: 10.1523/JNEUROSCI. 20-12-04563.2000

de Kloet, E. R., Sibug, R. M., Helmerhorst, F. M., and Schmidt, M. (2005). Stress, genes and the mechanism of programming the brain for later life. Neurosci. Biobehav. Rev. 29, 271-281. doi: 10.1016/j.neubiorev.2004.10.008

de Oliveira Alvares, L., Crestani, A. P., Cassini, L. F., Haubrich, J., Santana, F., and Quillfeldt, J. A. (2013). Reactivation enables memory updating, precisionkeeping and strengthening: exploring the possible biological roles of reconsolidation. Neuroscience 244, 42-48. doi: 10.1016/j.neuroscience.2013. 04.005

Di Segni, M., Andolina, D., and Ventura, R. (2018). Long-term effects of early environment on the brain: lesson from rodent models. Semin. Cell Dev. Biol. 77, 81-92. doi: 10.1016/j.semcdb.2017.09.039
Diamond, D. M., and Zoladz, P. R. (2015). Dysfunctional or hyperfunctional? The amygdala in posttraumatic stress disorder is the bull in the evolutionary china shop. J. Neurosci. Res. 94, 437-444. doi: 10.1002/jnr.23684

Diehl, L. A., Alvares, L. O., Noschang, C., Engelke, D., Andreazza, A. C., Gonçalves, C. A. S., et al. (2012). Long-lasting effects of maternal separation on an animal model of post-traumatic stress disorder: effects on memory and hippocampal oxidative stress. Neurochem. Res. 37, 700-707. doi: 10.1007/s11064-011-0660-6

Diehl, L. A., Pereira, N. D. S. C., Laureano, D. P., Benitz, A. N. D., Noschang, C., Ferreira, A. G. K., et al. (2014). Contextual fear conditioning in maternal separated rats: the amygdala as a site for alterations. Neurochem. Res. 39, 384-393. doi: 10.1007/s11064-013-1230-x

Diehl, L. A., Silveira, P. P., Leite, M. C., Crema, L. M., Portella, A. K., Billodre, M. N., et al. (2007). Long lasting sex-specific effects upon behavior and S100b levels after maternal separation and exposure to a model of post-traumatic stress disorder in rats. Brain Res. 1144, 107-116. doi: 10.1016/j. brainres.2007.01.084

Dunah, A. W., and Standaert, D. G. (2001). Dopamine D1 receptor-dependent trafficking of striatal NMDA glutamate receptors to the postsynaptic membrane. J. Neurosci. 21, 5546-5558. doi: 10.1523/JNEUROSCI.21-15 $-05546.2001$

Dunbar, A. B., and Taylor, J. R. (2017). Reconsolidation and psychopathology: moving towards reconsolidation-based treatments. Neurobiol. Learn. Mem. 142, 162-171. doi: 10.1016/j.nlm.2016.11.005

Eiland, L., and Romeo, R. D. (2013). Stress and the developing adolescent brain. Neuroscience 249, 162-171. doi: 10.1016/j.neuroscience.2012. 10.048

Elsey, J. W. B., and Kindt, M. (2017). Tackling maladaptive memories through reconsolidation: from neural to clinical science. Neurobiol. Learn. Mem. 142, 108-117. doi: 10.1016/j.nlm.2017.03.007

Espejo, P. J., Ortiz, V., Martijena, I. D., and Molina, V. A. (2016). Stressinduced resistance to the fear memory labilization/reconsolidation process. Involvement of the basolateral amygdala complex. Neuropharmacology 109, 349-356. doi: 10.1016/j.neuropharm.2016.06.033

Espejo, P. J., Ortiz, V., Martijena, I. D., and Molina, V. A. (2017). GABAergic signaling within the Basolateral Amygdala Complex modulates resistance to the labilization/reconsolidation process. Neurobiol. Learn. Mem. 144, 166-173. doi: 10.1016/j.nlm.2017.06.004

Fanselow, M. S., and Dong, H. W. (2010). Are the dorsal and ventral hippocampus functionally distinct structures? Neuron 65, 7-19. doi: 10.1016/j.neuron.2009. 11.031

Finsterwald, C., Steinmetz, A. B., Travaglia, A., and Alberini, C. M. (2015). From memory impairment to posttraumatic stress disorder-like phenotypes: the critical role of an unpredictable second traumatic experience. J. Neurosci. 35, 15903-15915. doi: 10.1523/JNEUROSCI.0771-15.2015

Franklin, T. B., Saab, B. J., and Mansuy, I. M. (2012). Neural mechanisms of stress resilience and vulnerability. Neuron 75, 747-761. doi: 10.1016/j.neuron.2012. 08.016

Gross, C. T., and Canteras, N. S. (2012). The many paths to fear. Nat. Rev. Neurosci. 13, 651-658. doi: 10.1038/nrn3301

Hall, J., Thomas, K. L., and Everitt, B. J. (2001). Cellular imaging of zif268 expression in the hippocampus and amygdala during contextual and cued fear memory retrieval: selective activation of hippocampal CA1 neurons during the recall of contextual memories. J. Neurosci. 21, 2186-2193. doi: 10.1523/JNEUROSCI.21-06-02186.2001

Hartley, C. A., and Phelps, E. A. (2010). Changing fear: the neurocircuitry of emotion regulation. Neuropsychopharmacology 35, 136-146. doi: 10.1038/npp. 2009.121

Haubrich, J., Crestani, A. P., Cassini, L. F., Santana, F., Sierra, R. O., Alvares, L. D. O., et al. (2015). Reconsolidation allows fear memory to be updated to a less aversive level through the incorporation of appetitive information. Neuropsychopharmacology 40, 315-326. doi: 10.1038/npp. 2014.174

Hoffman, A. N., Parga, A., Paode, P. R., Watterson, L. R., Nikulina, E. M., Hammer, R. P., et al. (2015). Chronic stress enhanced fear memories are associated with increased amygdala zif268 mRNA expression and are resistant to reconsolidation. Neurobiol. Learn. Mem. 120, 61-68. doi: 10.1016/j.nlm. 2015.02.004 
Holehonnur, R., Phensy, A. J., Kim, L. J., Milivojevic, M., Vuong, D., Daison, D. K., et al. (2016). Increasing the GluN2A/GluN2B ratio in neurons of the mouse basal and lateral amygdala inhibits the modification of an existing fear memory trace. J. Neurosci. 36, 9490-9504. doi: 10.1523/JNEUROSCI.1743-16.2016

Hsu, F.-C., Zhang, G.-J., Raol, Y. S. H., Valentino, R. J., Coulter, D. A., and BrooksKayal, A. R. (2003). Repeated neonatal handling with maternal separation permanently alters hippocampal GABAA receptors and behavioral stress responses. Proc. Natl. Acad. Sci. U S A 100, 12213-12218. doi: 10.1073/pnas. 2131679100

Jarome, T. J., Ferrara, N. C., Kwapis, J. L., and Helmstetter, F. J. (2016). CaMKII regulates proteasome phosphorylation and activity and promotes memory destabilization following retrieval. Neurobiol. Learn. Mem. 128, 103-109. doi: 10.1016/j.nlm.2016.01.001

Jarome, T. J., and Helmstetter, F. J. (2014). Protein degradation and protein synthesis in long-term memory formation. Front. Mol. Neurosci. 7:61. doi: 10.3389/fnmol.2014.00061

Jarome, T. J., Werner, C. T., Kwapis, J. L., and Helmstetter, F. J. (2011). Activity dependent protein degradation is critical for the formation and stability of fear memory in the amygdala. PLoS One 6:e24349. doi: 10.1371/journal.pone. 0024349

Kessler, R. C., McLaughlin, K. A., Green, J. G., Gruber, M. J., Sampson, N. A., Zaslavsky, A. M., et al. (2010). Childhood adversities and adult psychopathology in the WHO world mental health surveys. $\mathrm{Br}$. J. Psychiatry 197, 378-385. doi: 10.1192/bjp.bp.110.080499

Kindt, M., and van Emmerik, A. (2016). New avenues for treating emotional memory disorders: towards a reconsolidation intervention for posttraumatic stress disorder. Ther. Adv. Psychopharmacol. 6, 283-295. doi: $10.1177 / 2045125316644541$

Koe, A. S., Ashokan, A., and Mitra, R. (2016). Short environmental enrichment in adulthood reverses anxiety and basolateral amygdala hypertrophy induced by maternal separation. Transl. Psychiatry 6:e729. doi: 10.1038/tp.2015.217

Kopp, C., Longordo, F., and Lüthi, A. (2007). Experience-dependent changes in NMDA receptor composition at mature central synapses. Neuropharmacology 53, 1-9. doi: 10.1016/j.neuropharm.2007.03.014

Kosten, T. A., Kim, J. J., and Lee, H. J. (2012). Early life manipulations alter learning and memory in rats. Neurosci. Biobehav. Rev. 36, 1985-2006. doi: 10.1016/j.neubiorev.2012.07.003

Kosten, T. A., Lee, H. J., and Kim, J. J. (2006). Early life stress impairs fear conditioning in adult male and female rats. Brain Res. 1087, 142-150. doi: 10.1016/j.brainres.2006.03.009

Kosten, T. A., Lee, H. J., and Kim, J. J. (2007). Neonatal handling alters learning in adult male and female rats in a task-specific manner. Brain Res. 1154, 144-153. doi: 10.1016/j.brainres.2007.03.081

Ladd, C. O., Huot, R. L., Thrivikraman, K. V., Nemeroff, C. B., Plotsky, P. M., Bergant, A. M., et al. (2004). Long-term adaptations in glucocorticoid receptor and mineralocorticoid receptor mrna and negative feedback on the hypothalamo-pituitary-adrenal axis following neonatal maternal separation. Biol. Psychiatry 55, 367-375. doi: 10.1016/j.biopsych.2003.10.007

Lajud, N., Roque, A., Cajero, M., Gutiérrez-Ospina, G., and Torner, L. (2012). Periodic maternal separation decreases hippocampal neurogenesis without affecting basal corticosterone during the stress hyporesponsive period, but alters HPA axis and coping behavior in adulthood. Psychoneuroendocrinology 37, 410-420. doi: 10.1016/j.psyneuen.2011.07.011

Lamprecht, R. (2016). The role of actin cytoskeleton in memory formation in amygdala. Front. Mol. Neurosci. 9:23. doi: 10.3389/fnmol.2016. 00023

Lanius, R. A., Frewen, P. A., Vermetten, E., and Yehuda, R. (2010). Fear conditioning and early life vulnerabilities: two distinct pathways of emotional dysregulation and brain dysfunction in PTSD. Eur. J. Psychotraumatol. 1:5467. doi: 10.3402/ejpt.v1i0.5467

LeDoux, J. E. (2003). The emotional brain, fear, and the amygdala. Cell. Mol. Neurobiol. 23, 727-738. doi: 10.1023/A:1025048802629

Lee, S.-H., Choi, J.-H., Lee, N., Lee, H.-R., Kim, J.-I., Yu, N.-K., et al. (2008). Synaptic protein degradation underlies destabilization of retrieved fear memory. Science 319, 1253-1256. doi: 10.1126/science.1150541

Lee, J. L. C., Everitt, B. J., and Thomas, K. L. (2004). Independent cellular processes for hippocampal memory consolidation and reconsolidation. Science 304, 839-843. doi: 10.1126/science. 1095760
Liberzon, I., and Abelson, J. L. (2016). Context processing and the neurobiology of post-traumatic stress disorder. Neuron 92, 14-30. doi: 10.1016/j.neuron.2016. 09.039

Lunardi, P., Sachser, R. M., Sierra, R. O., Pedraza, L. K., Medina, C., de la Fuente, V., et al. (2018). Effects of hippocampal LIMK inhibition on memory acquisition, consolidation, retrieval, reconsolidation, and extinction. Mol. Neurobiol. 55, 958-967. doi: 10.1007/s12035-016-0361-x

Maddox, S. A., Monsey, M. S., and Schafe, G. E. (2011). Early growth response gene 1 (Egr-1) is required for new and reactivated fear memories in the lateral amygdala. Learn. Mem. 18, 24-38. doi: 10.1101/lm.19 80211

Makena, N., Bugarith, K., and Russell, V. A. (2012). Maternal separation enhances object location memory and prevents exercise-induced MAPK/ERK signalling in adult Sprague-Dawley rats. Metab. Brain Dis. 27, 377-385. doi: 10.1007/s11011-012-9298-6

Makkar, S. R., Zhang, S. Q., and Cranney, J. (2010). Behavioral and neural analysis of GABA in the acquisition, consolidation, reconsolidation, and extinction of fear memory. Neuropsychopharmacology 35, 1625-1652. doi: 10.1038/npp. 2010.53

Malkani, S., and Rosen, J. B. (2000). Differential expression of EGR-1 mRNA in the amygdala following diazepam in contextual fear conditioning. Brain Res. 860, 53-63. doi: 10.1016/s0006-8993(00)01976-4

Malkani, S., and Rosen, J. B. (2001). N-Methyl-D-aspartate receptor antagonism blocks contextual fear conditioning and differentially regulates early growth response-1 messenger RNA expression in the amygdala: implications for a functional amygdaloid circuit of fear. Neuroscience 102, 853-861. doi: 10.1016/s0306-4522(00)00531-5

Mao, S.-C., Lin, H.-C., and Gean, P.-W. (2008). Augmentation of fear extinction by D-cycloserine is blocked by proteasome inhibitors. Neuropsychopharmacology 33, 3085-3095. doi: 10.1038/npp.2008.30

Maren, S., Phan, K. L., and Liberzon, I. (2013). The contextual brain: implications for fear conditioning, extinction and psychopathology. Nat. Rev. Neurosci. 14, 417-428. doi: 10.1038/nrn3492

Mattiroli, F., and Sixma, T. K. (2014). Lysine-targeting specificity in ubiquitin and ubiquitin-like modification pathways. Nat. Struct. Mol. Biol. 21, 308-316. doi: $10.1038 / \mathrm{nsmb} .2792$

Meaney, M. J., Aitken, D. H., Bodnoff, S. R., Iny, L. J., Tatarewicz, J. E., and Sapolsky, R. M. (2013). Early postnatal handling alters glucocorticoid receptor concentrations in selected brain regions. Behav. Neurosci. 127, 637-641. doi: $10.1037 / \mathrm{a} 0034187$

Meerlo, P., Horvath, K. M., Nagy, G. M., Bohus, B., and Koolhaas, J. M. (1999). The influence of postnatal handling on adult neuroendocrine and behavioural stress reactivity. J. Neuroendocrinol. 11, 925-933. doi: 10.1046/j.1365-2826. 1999.00409.x

Milton, A. L., Lee, J. L. C., Butler, V. J., Gardner, R., and Everitt, B. J. (2008). Intra-amygdala and systemic antagonism of NMDA receptors prevents the reconsolidation of drug-associated memory and impairs subsequently both novel and previously acquired drug-seeking behaviors. J. Neurosci. 28 , 8230-8237. doi: 10.1523/JNEUROSCI.1723-08.2008

Milton, A. L., Merlo, E., Ratano, P., Gregory, B. L., Dumbreck, J. K., and Everitt, B. J. (2013). Double dissociation of the requirement for GluN2B- and GluN2A-containingNMDAReceptors in the destabilization and restabilization of a reconsolidating memory. J. Neurosci. 33, 1109-1115. doi: 10.1523/JNEUROSCI.3273-12.2013

Mokin, M., and Keifer, J. (2005). Expression of the immediate-early gene-encoded protein Egr-1 (zif268) during in vitro classical conditioning. Learn. Mem. 12, 144-149. doi: 10.1101/lm.87305

Nader, K., Schafe, G. E., and Le Doux, J. E. (2000). Fear memories require protein synthesis in the amygdala for reconsolidation after retrieval. Nature 406, 722-726. doi: 10.1038/35021052

Narayanan, R. T., Seidenbecher, T., Sangha, S., Stork, O., and Pape, H.-C. (2007). Theta resynchronization during reconsolidation of remote contextual fear memory. Neuroreport 18, 1107-1111. doi: 10.1097/wnr.0b013e32 82004992

Noschang, C., Krolow, R., Arcego, D. M., Toniazzo, A. P., Huffell, A. P., and Dalmaz, C. (2012). Neonatal handling affects learning, reversal learning and antioxidant enzymes activities in a sex-specific manner in rats. Int. J. Dev. Neurosci. 30, 285-291. doi: 10.1016/j.ijdevneu.2012.01.010 
Noschang, C. G., Krolow, R., Fontella, F. U., Arcego, D. M., Diehl, L. A., Weis, S. N., et al. (2010). Neonatal handling impairs spatial memory and leads to altered nitric oxide production and DNA breaks in a sex specific manner. Neurochem. Res. 35, 1083-1091. doi: 10.1007/s11064-010-0158-7

Olsen, R. W., and Sieghart, W. (2009). GABA A receptors: subtypes provide diversity of function and pharmacology. Neuropharmacology 56, 141-148. doi: 10.1016/j.neuropharm.2008.07.045

Ortiz, V., Giachero, M., Espejo, P. J., Molina, V. A., and Martijena, I. D. (2015). The effect of Midazolam and Propranolol on fear memory reconsolidation in ethanol-withdrawn rats: influence of d-cycloserine. Int. J. Neuropsychopharmacol. 18:pyu082. doi: 10.1093/ijnp/pyu082

Paxinos, G., and Watson, C. (1998). The Rat Brain in Stereotaxic Coordinates. 4th Edn. San Diego, CA: Academic Press.

Pedreira, M. E., Pérez-Cuesta, L. M., and Maldonado, H. (2002). Reactivation and reconsolidation of long-term memory in the crab chasmagnathus: protein synthesis requirement and mediation by NMDA-type glutamatergic receptors. J. Neurosci. 22, 8305-8311. doi: 10.1523/JNEUROSCI.22-18-08305.2002

Pedreira, M. E., Pérez-Cuesta, L. M., and Maldonado, H. (2004). Mismatch between what is expected and what actually occurs triggers memory reconsolidation or extinction. Mol. Neurobiol. 11, 579-585. doi: 10.1101/lm. 76904

Phillips, R. G., and LeDoux, J. E. (1992). Differential contribution of amygdala and hippocampus to cued and contextual fear conditioning. Behav. Neurosci. 106, 274-285. doi: 10.1037/0735-7044.106.2.274

Plotsky, P. M., Thrivikraman, K. V., Nemeroff, C. B., Caldji, C., Sharma, S., and Meaney, M. J. (2005). Long-term consequences of neonatal rearing on central corticotropin-releasing factor systems in adult male rat offspring. Neuropsychopharmacology 30, 2192-2204. doi: 10.1038/sj.npp.1300769

Popik, B., Crestani, A. P., Silva, M. O., Quillfeldt, J. A., and de Oliveira Alvares, L. (2018). Calpain modulates fear memory consolidation, retrieval and reconsolidation in the hippocampus. Neurobiol. Learn. Mem. 151, 53-58. doi: 10.1016/j.nlm.2018.04.002

Rehberg, K., Bergado-Acosta, J. R., Koch, J. C., and Stork, O. (2010). Disruption of fear memory consolidation and reconsolidation by actin filament arrest in the basolateral amygdala. Neurobiol. Learn. Mem. 94, 117-126. doi: 10.1016/j.nlm. 2010.04.007

Richter-Levin, G., and Akirav, I. (2000). Amygdala-hippocampus dynamic interaction in relation to memory. Mol. Neurobiol. 22, 11-20. doi: $10.1385 / \mathrm{mn}: 22: 1-3: 011$

Rodríguez-Manzanares, P. A., Isoardi, N. A., Carrer, H. F., and Molina, V. A. (2005). Previous stress facilitates fear memory, attenuates GABAergic inhibition, and increases synaptic plasticity in the rat basolateral amygdala. J. Neurosci. 25, 8725-8734. doi: 10.1523/JNEUROSCI.2260-05.2005

Romeo, R. D., Mueller, A., Sisti, H. M., Ogawa, S., McEwen, B. S., and Brake, W. G. (2003). Anxiety and fear behaviors in adult male and female C57BL/6 mice are modulated by maternal separation. Horm. Behav. 43, 561-567. doi: 10.1016/s0018-506x(03)00063-1

Rossato, J. I., Bevilaqua, L. R. M., Myskiw, J. C., Medina, J. H., Izquierdo, I., and Cammarota, M. (2007). On the role of hippocampal protein synthesis in the consolidation and reconsolidation of object recognition memory. Learn. Mem. 14, 36-46. doi: 10.1101/lm.422607

Sampath, D., Sabitha, K. R., Hegde, P., Jayakrishnan, H. R., Kutty, B. M., Chattarji, S., et al. (2014). A study on fear memory retrieval and REM sleep in maternal separation and isolation stressed rats. Behav. Brain Res. 273, 144-154. doi: 10.1016/j.bbr.2014.07.034

Schiller, D., Monfils, M.-H., Raio, C. M., Johnson, D. C., Ledoux, J. E., and Phelps, E. A. (2010). Preventing the return of fear in humans using reconsolidation update mechanisms. Nature 463, 49-53. doi: 10.1038/ nature 0863

Seidenbecher, T., Laxmi, T. R., Stork, O., and Pape, H.-C. (2003). Amygdalar and hippocampal theta rhythm synchronization during fear memory retrieval. Science 301, 846-850. doi: 10.1126/science.1085818
Singh-Taylor, A., Korosi, A., Molet, J., Gunn, B. G., and Baram, T. Z. (2015). Synaptic rewiring of stress-sensitive neurons by early-life experience: a mechanism for resilience? Neurobiol. Stress 1, 109-115. doi: 10.1016/j.ynstr. 2014.10.007

Sol Fustiñana, M., de la Federman, N., Freudenthal, N., Freudenthal, R., and Romano, A. (2014). Protein degradation by ubiquitin-proteasome system in formation and labilization of contextual conditioning memory. Learn. Mem. 21, 478-487. doi: 10.1101/lm.035998.114

Stevenson, C. W., Marsden, C. A., and Mason, R. (2008). Early life stress causes FG-7142-induced corticolimbic dysfunction in adulthood. Brain Res. 1193, 43-50. doi: 10.1016/j.brainres.2007.11.062

Stevenson, C. W., Meredith, J. P., Spicer, C. H., Mason, R., and Marsden, C. A. (2009). Early life programming of innate fear and fear learning in adult female rats. Behav. Brain Res. 198, 51-57. doi: 10.1016/j.bbr.2008. 10.021

Thome, J., Hauschild, S., Koppe, G., Liebke, L., Rausch, S., Herzog, J. I., et al. (2018). Generalisation of fear in PTSD related to prolonged childhood maltreatment: an experimental study. Psychol. Med. 48, 2223-2234. doi: $10.1017 / \mathrm{s} 0033291717003713$

Treisman, R. (1996). Regulation of transcription by MAP kinase cascades. Curr. Opin. Cell Biol. 8, 205-215. doi: 10.1016/s0955-0674(96)80067-6

Tronson, N. C., and Taylor, J. R. (2007). Molecular mechanisms of memory reconsolidation. Nat. Rev. Neurosci. 8, 262-275. doi: 10.1038/nrn2090

Van Marle, H. (2015). PTSD as a memory disorder. Eur. J. Psychotraumatol. 6:27633. doi: 10.3402/ejpt.v6.27633

Villain, H., Benkahoul, A., Birmes, P., Ferry, B., and Roullet, P. (2018). Influence of early stress on memory reconsolidation: implications for post- traumatic stress disorder treatment. PLoS One 13:e0191563. doi: 10.1371/journal.pone.01 91563

Wang, S.-H., de Oliveira Alvares, L., and Nader, K. (2009). Cellular and systems mechanisms of memory strength as a constraint on auditory fear reconsolidation. Nat. Neurosci. 12, 905-912. doi: 10.1038/ nn. 2350

Wilber, A. A., Southwood, C. J., and Wellman, C. L. (2009). Brief neonatal maternal separation alters extinction of conditioned fear and corticolimbic glucocorticoid and NMDA receptor expression in adult rats. Dev. Neurobiol. 69, 73-87. doi: 10.1002/dneu.20691

Winocur, G., Frankland, P. W., Sekeres, M., Fogel, S., and Moscovitch, M. (2009). Changes in context-specificity during memory reconsolidation: selective effects of hippocampal lesions. Cold Spring Harb. Lab. Press 16, 722-729. doi: 10.1101/lm.1447209

Xu, W., and Südhof, T. C. (2013). A neural circuit for memory specificity and generalization. Science 339, 1290-1295. doi: 10.1126/science.1229534

Yang, C.-H., Huang, C.-C., and Hsu, K.-S. (2011). Generalization of fear inhibition by disrupting hippocampal protein synthesis-dependent reconsolidation process. Neuropsychopharmacology 36, 1992-2008. doi: 10.1038/npp. 2011.87

Zhang, S., and Cranney, J. (2008). The role of GABA and anxiety in the reconsolidation of conditioned fear. Behav. Neurosci. 122, 1295-1305. doi: $10.1037 / \mathrm{a} 0013273$

Conflict of Interest Statement: The authors declare that the research was conducted in the absence of any commercial or financial relationships that could be construed as a potential conflict of interest.

Copyright (C) 2019 Couto-Pereira, Lampert, Vieira, Lazzaretti, Kincheski, Espejo, Molina, Quillfeldt and Dalmaz. This is an open-access article distributed under the terms of the Creative Commons Attribution License (CC BY). The use, distribution or reproduction in other forums is permitted, provided the original author(s) and the copyright owner(s) are credited and that the original publication in this journal is cited, in accordance with accepted academic practice. No use, distribution or reproduction is permitted which does not comply with these terms. 